\title{
Diazine-based thermally activated delayed fluorescence chromophores
}

\author{
Sylvain Achelle, ${ }^{{ }^{\mathrm{a}}}$ Maxime Hodée, ${ }^{\mathrm{a}}$ Julien Massue, ${ }^{\mathrm{b}}$ Arnaud Fihey, ${ }^{\mathrm{a}}$ and Claudine Katan, ${ }^{\mathrm{a}}$ \\ ${ }^{\text {a }}$ Univ Rennes, CNRS, ISCR (Institut des Sciences Chimiques de Rennes) - UMR 6226, F- \\ 35000 Rennes, France. E-mail: sylvain.achelle@univ-rennes1.fr \\ b Institut de Chimie et Procédés pour l'Energie, l'Environnement et la Santé (ICPEES), \\ Equipe Chimie Organique pour la Biologie, les Matériaux et l'Optique (COMBO), UMR \\ CNRS 7515, Ecole Européenne de Chimie, Polymères et Matériaux (ECPM), 25 Rue \\ Becquerel, 67087 Strasbourg, Cedex 02, France
}

\section{TOC}

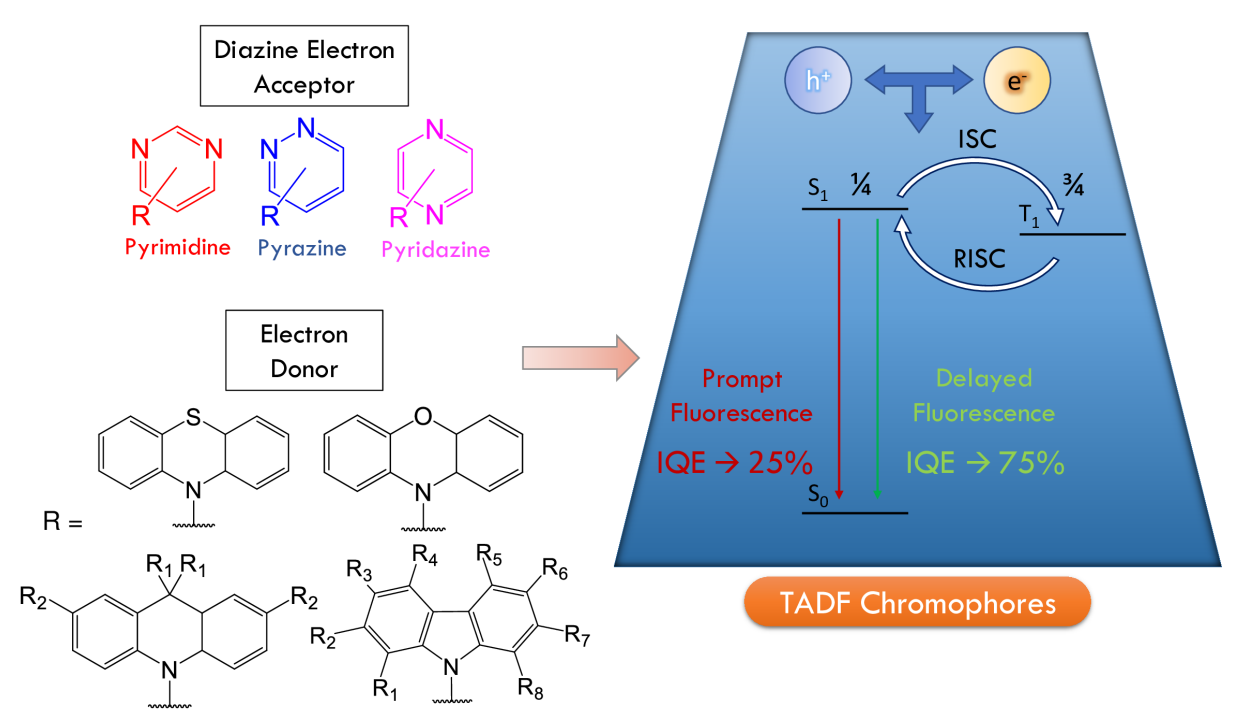

\begin{abstract}
Diazines are electron deficient six-membered aromatic rings heterocycles which have successfully been employed in the design of a wide range of push-pull chromophores for various applications in the field of organic electronics and optoelectronics. For instance, some have been specifically designed to be inserted in the electroluminescent emission layer of organic light emitting diodes (OLED). OLED technology has continuously evolved and is currently used in industry for display and lighting purposes, offering many advantages including low turn-on voltage and power consumption. In the prospect to further reduce energy waste, a third generation of OLED based on thermally activated delayed fluorescence (TADF), which allows harvesting both triplet and singlet excitons, attracts increasing attention from the scientific community. In this review, we provide a comprehensive overview of the present status of diazine-based dyes developed for TADF. The pyrimidine core is by far the most used and has demonstrated deep blue, blue or sky-blue and green emission when combined with carbazole, acridan and phenoxazine fragments, respectively. Further design of TADF emitters is desirable to afford red OLED and both the pyrazine and pyridazine cores have been scarcely explored.
\end{abstract}




\section{Introduction}

Thermally activated delayed fluorescence (TADF) is a photophysical process observed in selected organic luminophores which involves both singlet and triplet excited states. ${ }^{1,2}$ After photoexcitation, population of the accessible and stabilized triplet state occurs via the singlet state through intersystem crossing (ISC). In some cases, the thermal energy can promote back transfer through reverse intersystem crossing (RISC) from the triplet state to the singlet state and lead to delayed luminescence from singlet excited state (Figure 1). The involvement of a metastable triplet state delays the fluorescence process up to several microseconds $(\mu \mathrm{s})$ which represents a significant delayed lifetime, as compared to typical short-lived fluorescence occurring in the nanosecond (ns) range. In most cases, the lowenergy triplet state lies below the lowest excited singlet state and RISC is endothermal with stronger emission at higher temperature. The energy required to populate the singlet state via RISC is thus of thermal nature and a small singlet-triplet energy splitting ( $\Delta \mathrm{E}_{\mathrm{ST}}$, Figure 1$)$ between triplet and singlet excited states is needed. Most publications report a threshold value of $\Delta \mathrm{E}_{\mathrm{ST}}<0.1 \mathrm{eV}$.

Purely organic TADF chromophores generally display an electrodonor-acceptor (EDEA) push-pull structure with ED and EA being quasi-orthogonally connected, thereby reducing the overlap between the highest occupied molecular orbital (HOMO) and lowest unoccupied molecular orbital (LUMO) and in turn $\Delta \mathrm{E}_{\mathrm{ST} .}{ }^{3,4,5}$ This can be obtained by introducing bulky and/or spiro substituents on the molecular backbone. It should be noted however that strictly orthogonal conformation between EA and ED parts should be avoided to ensure non-vanishing spin-orbit coupling (SOC) between the singlet and triplet excited state. In fact, a finite SOC matrix element is desirable to harvest triplet states and allow ISC/RISC. ${ }^{6}$ Moreover, the nature of triplet and singlet excited states is also key for TADF: a low-lying triplet state with a local exciton nature $\left({ }^{3} \mathrm{LE}\right)$ nearby a low-lying singlet excited state with a strong charge transfer character $\left({ }^{1} \mathrm{CT}\right)$ is often a favorable situation. ${ }^{7,8}$ This simplified view of TADF has recently been extended and complexified by probing the role in the activation energy of ISC/RISC process of, not only the singlet-triplet energy gaps, but also their reorganization energies as well as higher-lying excited states. ${ }^{9}$ In addition, vibrational SOC and/or spin-vibronic model have recently been proposed to reach a better first-principle description of TADF, instead of the pure electronic SOC. ${ }^{10}$

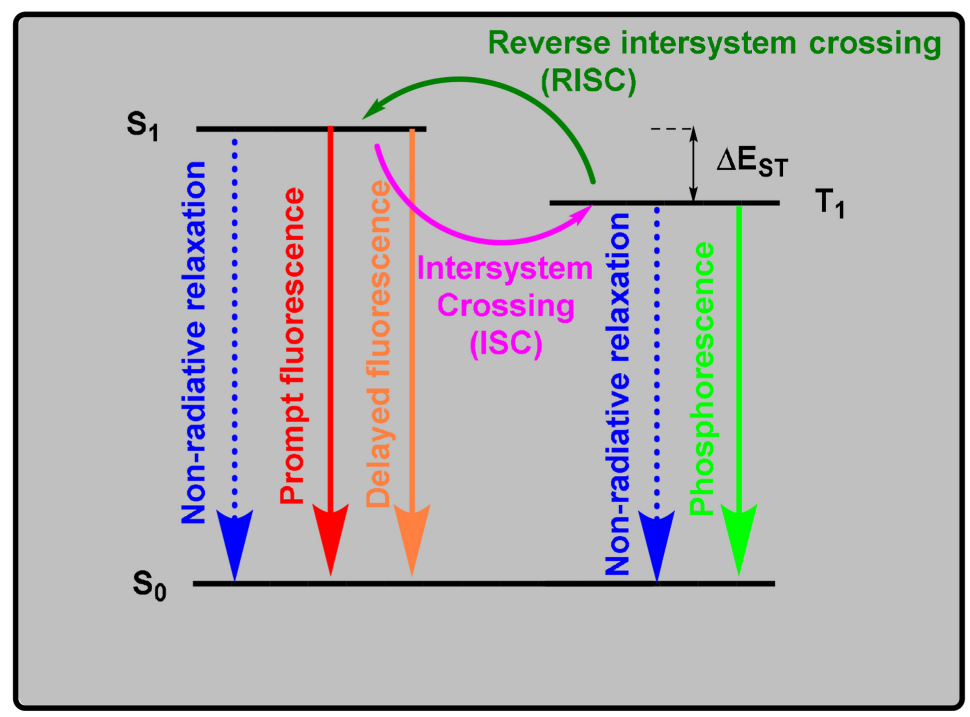

Figure 1: Minimalist schematic representation of various de-excitation channels from the first singlet $\left(\mathrm{S}_{1}\right)$ and triplet states $\left(\mathrm{T}_{1}\right)$ to the ground state $\left(\mathrm{S}_{0}\right)$. 
Described for the first time in the 1960s, ${ }^{11}$ the TADF phenomenon remained anecdotic for several decades until the pioneer work of Adachi, who reported for the first time an organic light-emitting diode (OLED) device based on a TADF emitter. ${ }^{12,13}$ First generation OLED were based on conventional fluorescent emitters, which limited their internal quantum efficiency (IQE) to $25 \%$, taking into account that only singlet excitons can be involved in the emission process. Indeed, simple spin statistics predicts that electrogenerated excitons display a singlet/triplet population ratio of $25: 75 .{ }^{14}$ This led to external quantum efficiency (EQE) values below $5 \%$, for most of the first-generation OLEDs. The second-generation OLEDs, also called phosphorescent OLED (PhOLED), are based on phosphorescent emitters which can harvest both triplet and singlet excitons ${ }^{2,15}$ leading to theoretical IQE of $100 \%$ and EQE that can reach $30 \%{ }^{16,17}$ The phosphorescent emitters used in PhOLED are often organometallic complexes of heavy metals (iridium, platinum, osmium...) characterized by their low abundance on earth, high cost, and potential toxicity. In this context, development of a third generation OLEDbased on TADF chromophores appears as a promising alternative. ${ }^{1,2,18,19}$ In addition to high stability and high luminance efficiency along with metalfree composition, all-organic TADF emitters allow production of a stable deep-blue light, which has always been problematic for the second-generation OLEDs. ${ }^{20}$

In this context, theoretical studies using quantum mechanics and especially Density Functional Theory (DFT) and its Time-Dependent version (TD-DFT) have shown their effectiveness to contribute to the understanding of the relationship between molecular structure and TADF features, but also for tailored molecular engineering. DFT and TD-DFT are often relevant methods to probe the geometries and electronic structure of the ground and excited states involved in the luminescence processes, respectively. First and foremost, they provide information on the molecular geometry and the likeliness of coplanar or twisted orthogonal conformations. TD-DFT is often used to assess the nature of singlet and triplet excited states as well as vertical excitation and deactivation energies and oscillator strengths. Because ISC and RISC are key quantities in the TADF process, DFT and TD-DFT have also been implemented to quantify the main parameters driving these intersystem crossings, namely $\Delta \mathrm{E}_{\mathrm{ST}}$, SOC matrix elements and vibronic coupling to the nuclear degrees of freedom. For instance, the semi-classical Marcus theory grants access to ISC/RISC rate constants with a vertical description of the $S_{n}$ and $T_{n}$ at the TD-DFT level. ${ }^{21,22}$ Although more complex firstprinciple approaches, based on (spin)-vibronic models, have been recently proposed to explore the TADF mechanism, ${ }^{10,23,24}$ the semi-classical theory remains a popular tool to rationalize and predict the impact of chemical substitution and establish structure-TADF properties relationships. ${ }^{25,26,27,28}$ Noteworthy, even so DFT and TD-DFT are first-principles approaches, they still face challenges related to the unknown exact expression of the exchange-correlation kernel, ${ }^{29,30}$ that might for instance lead to low-lying spurious CT states, and even state-of-the art TD-DFT solvation models may not reach chemical accuracy. ${ }^{31}$

The diazine derivatives are six-membered aromatic heterocycles comprising of two nitrogen atoms in their structure. Depending on the position of the nitrogen atoms, several types of azine rings can be obtained: pyridazine (1,2-diazine), pyrimidine (1,3-diazine) and pyrazine (1,4-diazine) (Figure 2). Due to the significant electron-deficiency of these heterocycles, the diazinyl fragments can be used as electron-withdrawing parts in push-pull structures. ${ }^{32,33,34}$ In the past two decades, numerous diazine fluorophores, mainly pyrimidine and pyrazine derivatives, have been described with applications ranging from sensing to bioimaging. ${ }^{35,36}$ Diazine building blocks have also been extensively used in the structure of optoelectronic materials. ${ }^{32-34,36,37}$ Except their reversible sensibility to acid, ${ }^{38}$ aryl-substituted diazine chromophores are characterized by their long term chemical stability. The emission properties of diazine chromophores can be finely tuned by structural modifications and 
external stimuli. ${ }^{38,39}$ In the first years of development of TADF emitters, 1,3,5-triazine derivatives have been widely employed as an EA part, ${ }^{12,40,41}$ though the possibilities of functionalization of this heterocycle are rather limited. ${ }^{42}$ More recently the pyrimidine, possessing less stabilized empty $\pi$-orbitals, has been proposed as an alternative to $1,3,5-$ triazine. This is in particular due to the fact that pyrimidine chromophores are generally more emissive than triazine analogues. ${ }^{43}$ Pyrazine TADF chromophores have emerged only in the past two years and pyridazine TADF chromophores remain scarce. Since 2016, around a hundred diazine-based TADF chromophores have been described as good candidates for OLED applications. This review, whose scope includes an extensive overview of the diazinebased TADF chromophores reported to date, aims at updating and complementing a first review published in 2018 by Kido and coworkers, ${ }^{44}$ on pyrimidine-based OLEDs. This review will not cover benzodiazine (quinoxaline, quinazoline...) derivatives. At the time of submitting our review, we learned about a recently published review article on multipath exciton harvesting in diazine-based luminescent materials for OLED application. ${ }^{45}$

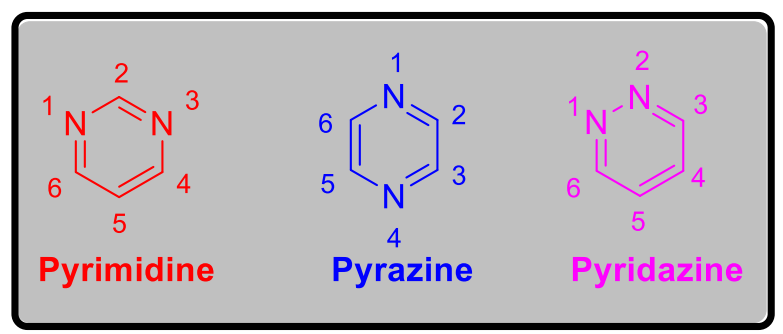

Figure 2: Structure of the diazine rings.

Bulky or spiro ED parts described in TADF push-pull chromophores derive almost exclusively from amino carbazole, 9,10-dihydroacridine, phenoxazine and phenothiazine moieties (Figure 3). ${ }^{1,2}$ It should be mentioned that commercial carbazole can contain a trace amount of isomeric impurity (1H-benz[f]indole) that has a significant effect on luminescent properties especially phosphorescence and some published data may be due to this trace isomeric impurity. ${ }^{46}$ In the core of this review, each paragraph will be dedicated to the description of TADF dyes substituted with one of the three diazine derivatives (pyrimidine, pyrazine or pyridazine) which will be further divided according to the type of ED groups implemented on the organic scaffold. In the following, whenever possible, structure properties relationships will be described through the scope of TADF properties and OLED performances.

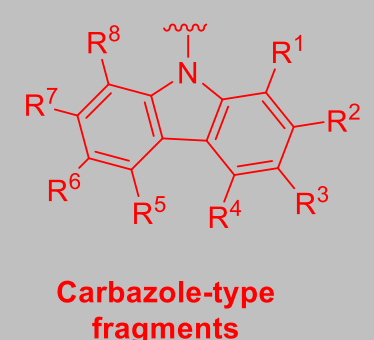

fragments

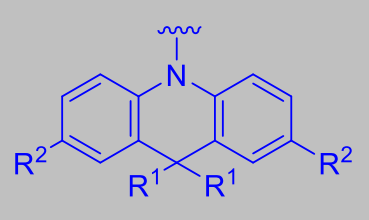

Dihydroacridine-type fragments

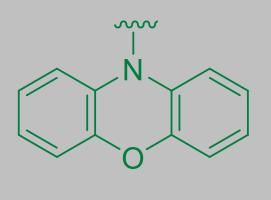

Phenoxazine fragment

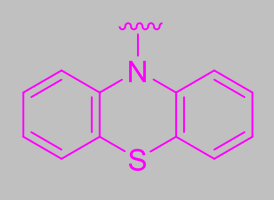

Phenothiazine fragment

Figure 3 : Structure of ED groups used in push-pull TADF chromophores.

\section{Pyrimidine chromophores}

Among the three diazines, pyrimidine is clearly the most used in the structure of TADF emitters reported to date. So far, they have (mainly) been combined with carbazole, dihydroacridine, phenoxazine or phenothiazine substituents that will be reviewed one by one. 


\section{Carbazole substituents}

The carbazole fragments are one of the common ED groups that can be used in the structure of TADF chromophores. In this case, however, the central pyrrole ring of carbazole is not always able to induce sufficiently large steric effect to maintain a quasi-perpendicular arrangement with the EA part of the push-pull structure upon excitation necessary to observe spatially separated HOMO and LUMO orbitals and small enough $\Delta \mathrm{E}_{\mathrm{ST}}{ }^{47,48}$ The carbazole fragments can be connected directly to the pyrimidine core by simple nucleophilic substitution or by Buchwald-Hartwig Pd-catalyzed cross-coupling reaction from chloropyrimidine derivatives, ${ }^{49}$ whereas 9 -phenyl-9H-carbazole fragments can be grafted onto the pyrimidine core by Pd-catalyzed Suzuki cross-coupling reaction from chloropyrimidine derivatives and the corresponding boronic acids/esters, ${ }^{50}$ by Ullman coupling from the corresponding bromophenylpyrimidine ${ }^{51}$ or by nucleophilic substitution from the corresponding fluorophenylpyrimidine. ${ }^{52}$

Serevičius and coworkers have designed a couple of 4,6-di( $9 H$-carbazol-9-yl)pyrimidine derivatives 1 (Chart 1). ${ }^{49}$ These chromophores exhibit $\Delta \mathrm{E}_{\mathrm{ST}}$ significantly higher than $0.1 \mathrm{eV}$ (Table 1) and do not show any TADF properties in solution but TADF can be observed when doped in $1 \mathrm{wt} \%$ polymethylmetacrylate (PMMA) thin films for compound 2, as shown by $\mathrm{O}_{2}$ sensibility and temperature activation experiments. DFT calculations indicate that the methyl group at the $\mathrm{C} 5$ position of the pyrimidine ring (Figure 2) clearly increased the twisting angle between ED and EA units, thereby reducing the $\Delta \mathrm{E}_{\mathrm{ST}}$ value. Calculations indicate also that the $\mathrm{S}_{0} \rightarrow \mathrm{T}_{1}$ and $\mathrm{S}_{0} \rightarrow \mathrm{T}_{2}$ transitions have LE characters. Compound 2 has been further used in the emissive layer of an OLED, leading to a deep blue TADF OLED with EQE as high as $8.7 \%$, which is comparable to other efficient deep-blue OLED (Table 2). Grazulivicius and coworkers have also designed 5-cyanopyrimidine derivatives $\mathbf{2}$ bearing two carbazole fragments in position 4 and 6 (Chart 1). ${ }^{53}$ These compounds all exhibit TADF properties with delayed fluorescence (Table 1), even if the photoluminescence quantum yields (PLQY) is significantly decreased when the carbazole fragments are substituted by methoxy groups (compounds $\mathbf{2 c}$ ). These compounds are described as potential oxygen sensors.

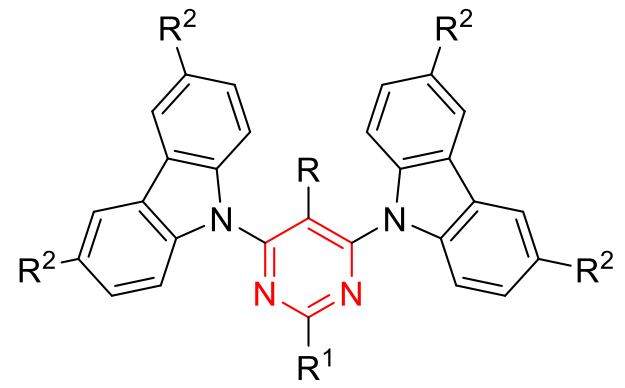

$$
\begin{aligned}
& \text { 1a } R=R^{1}=R^{2}=H \\
& \text { 1b } R=M e, R^{1}=S M e, R^{2}={ }^{t} B u \\
& \text { 2a } R=C N, R^{1}=R^{2}=H \\
& \text { 2b } R=C N, R^{1}=H, R^{2}={ }^{t} B u \\
& \text { 2c } R=C N, R^{1}=H, R^{2}=O M e
\end{aligned}
$$

Chart 1. Structure of 4,6-di(9H-carbazol-9-yl)pyrimidine derivatives 1 and $\mathbf{2}$

Li, Liu and coworkers have designed 2-(9H-carbazol-9-yl)phenylpyrimidine 3 (Chart 2). ${ }^{54}$ The steric hindrance effect of the methyl group in capable of facilitating donor twisting and $\mathrm{HOMO} / \mathrm{LUMO}$ separation and lead to TADF even if $\Delta \mathrm{E}_{\mathrm{ST}}$ remains higher than $0.1 \mathrm{eV}$ (Table 1). Compared to 1,3,5-triazine analogue, the chromophore 3 exhibits $15 \mathrm{~nm}$ blue shifted emission. A pure blue TADF OLED with 3 as emitter was realized with an EQE of $7.53 \%$, slightly lower than 1,3,5-triazine analogue probably due to a rather long delayed fluorescence lifetime (Table 2). The authors claimed however than device efficiencies still have opportunity to be optimized.

Initially described by Tumkevičius, Skardziute and coworkers, ${ }^{50,55}$ the 4,6-bis(4- $(9 H-$ carbazol-9-yl)phenyl)pyrimidines 4-6 (Chart 2) were later studied for their TADF properties 
by Serevičius et al. ${ }^{56}$ DFT calculations indicate for these compounds that the dihedral angle between the phenyl and the carbazole fragment is around $55^{\circ}$. In all cases, the $\mathrm{S}_{0} \rightarrow \mathrm{S}_{1}$ transition has an ICT character (more pronounced for $\mathbf{6 b}$ ) and the $\mathrm{S}_{0} \rightarrow \mathrm{T}_{1}$ transition expresses a strong LE feature. For compounds $\mathbf{5}$ and $\mathbf{6 b}$, the presence of respectively thiomethyl and dimethylaminophenyl fragments at the $\mathrm{C} 2$ position of the pyrimidine core (Figure 2) reduces the $\Delta \mathrm{E}_{\mathrm{ST}}$ and enhances the RISC (Table 1). This is most likely responsible for the TADF observed in doped PMMA thin films with these two compounds. It should be noted that the PLQY of doped PMMA thin filmss of $\mathbf{5}$ and $\mathbf{6 b}$ in vacuum are significantly higher than in $\mathrm{O}_{2}$ atmosphere, which is not the case for chromophores $\mathbf{4}$ and 6a. An OLED with chromophore 6b as emitter exhibiting sky-blue emission was fabricated with moderate EQE value (Table 2).<smiles>Cc1cccc2c3ccccc3n(-c3ccc(-c4nc(-c5ccccc5)cc(-c5ccccc5)n4)cc3)c12</smiles><smiles>[R]c1nc(-c2ccc(-n3c4ccccc4c4ccccc43)cc2)cc(-c2ccc(-n3c4ccccc4c4ccccc43)cc2)n1</smiles><smiles>CCCc1ccc(C=Cc2ccc(N(C)C)cc2)cc1</smiles>
3

Chart 2. Structure of 2-(9H-carbazol-9-yl)phenylpyrimidine 3 and (4,6-bis(4-(9H-carbazol9-yl)phenyl)pyrimidines 4-6

The same research group designed polycarbazole-substituted 2,4-diphenylpyrimidines 7-9 (Chart 3). ${ }^{57,58}$ According to results observed with compounds $\mathbf{4}$ and $\mathbf{6 a}$, the bis-substituted pyrimidine with carbazole units at the para position, as in chromophore 7a does not exhibit any TADF properties but when the carbazoles are substituted at the meta position (compound 8 and 9), a significant decrease of $\Delta \mathrm{E}_{\mathrm{ST}}$ is observed leading to delayed emission (Table 1). Even if the PLQY remains low for $\mathbf{8}$, the addition of carbazole groups at the meta position significantly enhances the PLQY without drastically increasing $\triangle \mathrm{E}_{\mathrm{ST}}$. An efficient blue OLED with compound 9 as emitter with a nearly 20\% EQE has been reported. Compound $7 \mathbf{b}$ with diphenylamino substituent on the carbazole fragments exhibit delayed fluorescence emission. Efficient green electroluminescence with an $\mathrm{EQE}_{\max }$ of $18.3 \%$ was showed for an OLED with $\mathbf{7 b}$ as emitter (Table 2).<smiles>[R]c1ccc(-c2cc(-c3ccc([R])cc3)ncn2)cc1</smiles><smiles>[R]c1cc([R])cc(-c2cc(-c3cc([R])cc([R])c3)ncn2)c1</smiles><smiles>[R]c1cc(-c2cc(-c3cc([R])c([R])c([R])c3)ncn2)cc([R])c1[R]</smiles><smiles>[R]Cn1c2ccc([X])cc2c2cc([X])ccc21</smiles>

Chart 3. Structure of polycarbazole-substituted 2,4-diphenylpyrimidines 7-9 
Polgar and coworkers studied a series of potential TADF chromophores based on biphenylmethylacrylate substituted pyrimidine fragment (Chart 4). ${ }^{59}$ Various ED groups, including carbazole, were used either at $\mathrm{C} 4 / \mathrm{C} 6$ or $\mathrm{C} 2$ position of the pyrimidine ring (Figure 2). In toluene, all compounds exhibit high PLQY with sensitivity to the presence of $\mathrm{O}_{2}$ (Tables 1, 3 and 5). The unsubstituted carbazole chromophore 10d possesses a rather large $\Delta \mathrm{E}_{\mathrm{ST}}$ value $(0.66 \mathrm{eV})$ and it is thus not surprising that it does not present any delayed fluorescence. The addition of bis para-tolylamino groups on the carbazole fragment reduces $\Delta \mathrm{E}_{\mathrm{ST}}$ by an order of magnitude, which leads compound 10e to undergo delayed emission (Table 1). As will be highlighted in the forthcoming sections, phenoxazine and phenothiazine derivatives 10b and 10c also exhibit TADF (Table 5) as opposed to dimethylacridine chromophores 10a and 12a (Table 3). Noteworthy, this behavior correlates directly with the magnitude of $\Delta \mathrm{E}_{\mathrm{ST}}$. The presence of the ED group in $\mathrm{C} 2$ position instead of $\mathrm{C} 4 / \mathrm{C} 6$ position (Figure 2 and Chart 4) triggers a blue-shift of the emission peak, with a decrease of PLQY and an increase of $\Delta \mathrm{E}_{\mathrm{ST}}$ for compound 12a as compared to 10a (Table 3). Replacement of one of the two dimethylacridine fragments by a phenoxazine one, as implemented in compound 11a, allows for delayed emission to take place thanks to significant reduction of $\Delta \mathrm{E}_{\mathrm{ST}}$ (Table $3)$. The chromophores 10-12 were further used for copolymerization with 4-(9H-fluoren-9yl)benzyl acrylate and the corresponding copolymers display delayed emission in thin films except for the one based on the carbazole monomer $\mathbf{1 0 d}$.<smiles>C=CC(=O)OCc1ccc(-c2ccc(-c3nc(-c4ccc(C(=O)OC)cc4)cc(-c4ccc(C(=O)OCC)cc4)n3)cc2)cc1</smiles>
10a-e

$\mathrm{ED}=$<smiles>[X]c1ccccc1N(C)c1ccccc1[X]</smiles>

(a) $X=\mathrm{CMe}_{2}$ (b) $\mathrm{X}=\mathrm{O}$ (c) $\mathrm{X}=\mathrm{S}$<smiles>C=CC(=O)OCc1ccc(-c2ccc(-c3nc(-c4ccc(C#P)cc4)cc(-c4ccc(N5c6ccccc6Oc6ccccc65)cc4)n3)cc2)cc1</smiles><smiles>C=CC(=O)OCc1ccc(-c2ccc(-c3cc(-c4ccccc4)nc(-c4ccc(C#P)cc4)n3)cc2)cc1</smiles><smiles>CN1c2ccccc2-c2ccccc2[W]1=O</smiles>

(d)<smiles>Cc1ccc(N(c2ccc(C)cc2)c2ccc3c(c2)c2cc(N(c4ccc(C)cc4)c4ccc(C)cc4)ccc2n3C)cc1</smiles>

Chart 4. Structure of acrylate substituted pyrimidine chromophores 10-12.

Another strategy consists in introducing bulkier and constrained carbazole fragments into the molecular backbone. Following this line, Zhang and coworkers have designed derivatives 13 and 14 using $5 H$-benzofuro- and $5 H$-benzothieno[3,2-c]carbazole ED groups (Chart 5). ${ }^{51}$ Both derivatives exhibit similar photophysical properties, with slightly lower $\triangle \mathrm{E}_{\mathrm{ST}}$, PLQY and delayed emission lifetime for the oxygen derivative 13 (Table 1). Deep blue emitting 
OLEDwith $\mathrm{EQE}_{\max }$ of $6.2 \%$ and 5,4\% were fabricated, respectively with 13 and $\mathbf{1 4}$ in the emissive layer, which are among the best performances reported so far for this color range (Table 2).

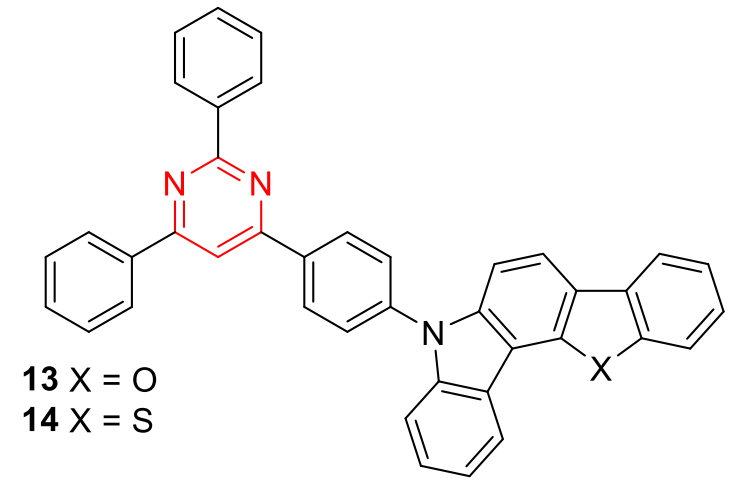

Chart 5. Structure of triphenylpyrimidines 13 and 14.

Gómez-Bonbarelli et al have designed the chromophores 15-17 (Chart 6) selected as promising TADF chromophores out of the 400,000 structures obtained using high throughput virtual screening based on TD-DFT. ${ }^{60}$ The structures of compounds $\mathbf{1 5}$ and $\mathbf{1 6}$ consist in diphenylaminocarbazole derivatives but differ by the position of the ED group on the pyrimidine core, whereas the structure of compound $\mathbf{1 7}$ is based on a indolocarbazole central core. The chromophore 15 with the ED group at the $\mathrm{C} 4$ position of the pyrimidine ring (Figure 2) exhibits a significantly lower $\Delta \mathrm{E}_{\mathrm{ST}}$ value $(60 \mathrm{meV}$ in toluene, Table 1) and a higher PLQY as compared to compound $\mathbf{1 6}$ in which the ED group is grafted onto the C2 position of the pyrimidine core. Compound $\mathbf{1 7}$ shows comparable PLQY but a greater $\Delta \mathrm{E}_{\mathrm{ST}}$, inducing lower efficiency in RISC. Not surprisingly, when included in an OLED (10\% emissive molecules doped in bis[2-(diphenylphosphino)phenyl] ether oxide (DPEPO)), compound 16 demonstrates an $\mathrm{EQE}_{\max }$ as high as $22 \%$ (Table 2).
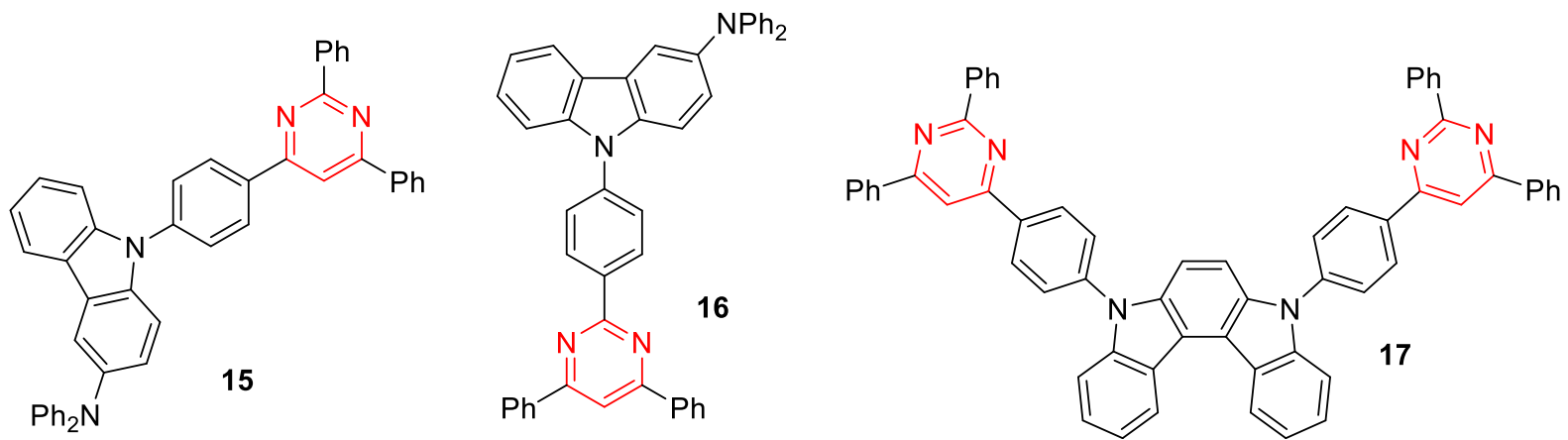

Chart 6. Structure of diphenylaminocarbazole 15 and $\mathbf{1 6}$ and indolocarbazole $\mathbf{1 7}$

Jang and coworkers designed 5-cyanopyrimidine derivatives 18-20 with indolocarbazole and bicarbazole ED fragments (Chart 7). ${ }^{52,61}$ The influence of the nature and the position of the ED group on the pyrimidine core and the phenyl linker was thoroughly studied. These compounds exhibit the classical twisted ED-EA structure, typically encountered among TADF chromophores. DFT calculations indicate that for compounds $\mathbf{1 8}$ ground state geometry, the phenyl linker is nearly co-planar with the pyrimidine core whereas an angle of about $35^{\circ}$ is observed for compounds 19, due to the adjacent cyano group that prevents hydrogen bond formation and distorts the phenyl unit from the pyrimidine-5-carbonitrile plane. The angles between the phenyl linker and the ED groups were about $70^{\circ}$ and $50^{\circ}$ in indolocarbazoles 18a and 19a and bicarbazoles $18 \mathrm{~b}$ and 19b. This value is higher $\left(66^{\circ}\right)$ for 
compound 20b due to increased steric hindrance. The angle between the pyrimidine and the phenyl linker is also significantly higher $\left(53^{\circ}\right)$. When comparing chromophores $\mathbf{1 8}$ and $\mathbf{1 9}$, two main trends can be observed: i) the presence of the donor in the $\mathrm{C} 4$ position of the pyrimidine (compounds 19) tends to decrease the $\Delta \mathrm{E}_{\mathrm{ST}}$ value and ii) the presence of the indolocarbazole ED group leads to an increase of the prompt emission and a decrease of the delayed fluorescence lifetimes (Table 1). In the case of $\mathbf{2 0 b}$, the steric hindrance drastically reduces $\Delta \mathrm{E}_{\mathrm{ST}}$, down to $0.02 \mathrm{eV}$. This compound has also a significantly decreased delayed fluorescence lifetime $(2.4 \mu \mathrm{s}$ compared to $12.8 \mu \mathrm{s}$ for regioisomer 19b). Green emitting OLEDs were obtained with compounds 18-20. The highest EQE values (19.8\%) are observed for 19b (Table 2) and the device with $\mathbf{2 0 b}$ as emitter showed a shorter lifetime, to be correlated with a faster RISC process for this compound.
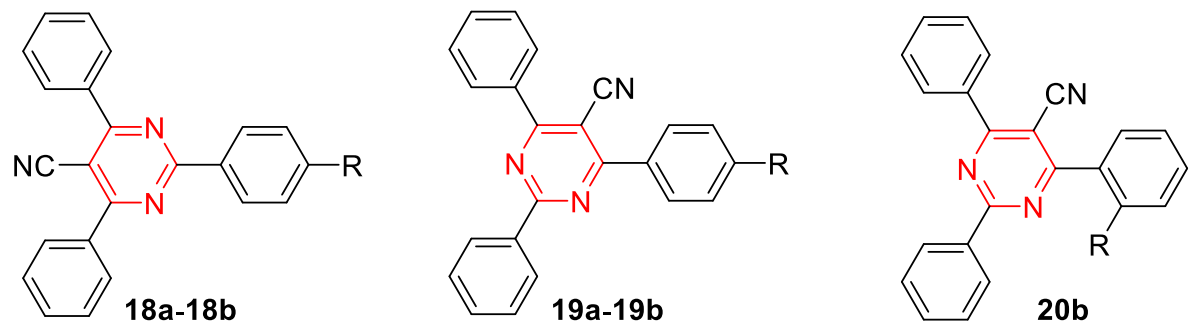

(a) $\mathrm{R}=$<smiles>Cn1c2ccccc2c2c3c4ccccc4n(-c4ccccc4)c3ccc21</smiles>

(b) $\mathrm{R}=$

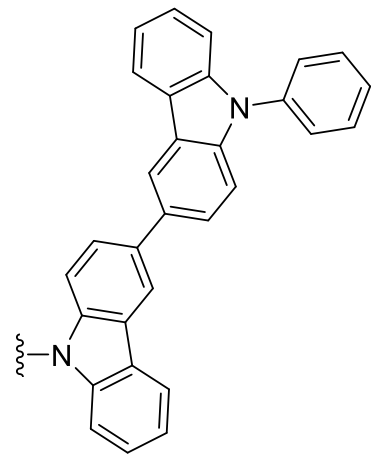

Chart 7. Structure of 5-cyanopyrimidines 18-20

The pyrimidine ring, which is generally used as EA, can also be used as linker with EA character, as reported by Lays dos Santos et al with the structure of emitter 21 (Chart 8). ${ }^{62}$ This compound exhibits a lower $\Delta \mathrm{E}_{\mathrm{ST}}$ value and shorter delayed fluorescence lifetime than pyridine; two beneficial features for TADF OLED applications. Incorporated in the emissive layer of an OLED, compound 21 shows blue emission with an EQE of 14\% (Table 2). This device displays improved EQE and efficiency roll-off, which is nonetheless at the cost of color purity with regards to similar devices prepared with pyridine analogues of $\mathbf{2 1}$. These improvements were rationalized by DFT ground state geometry optimization that revealed a more planar ED-bridge conformation. It should also be noted that various carbazole pyrimidine hybrid materials have been designed as host materials for TADF based third generation OLEDs. ${ }^{63,64,65}$

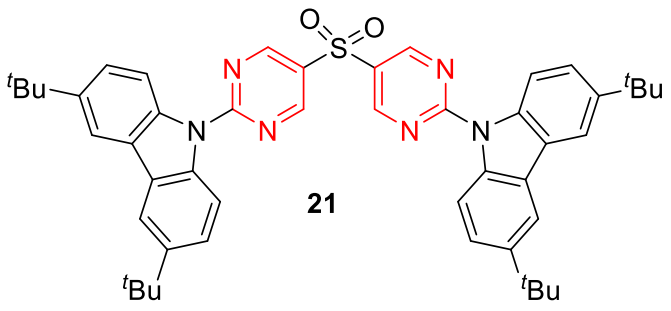

Chart 8. Structure of bispyrimidine chromophore 18 
Table 1: Photophysical data of carbazole substituted pyrimidine TADF chromophores

\begin{tabular}{|c|c|c|c|c|c|}
\hline Compds & $\Delta E_{S T}(e V)$ & $\lambda_{\mathrm{em}}(\mathrm{nm})$ & PLQY & $\tau_{\mathrm{PF}}(\mathrm{ns}) / \tau_{\mathrm{DF}}(\mu \mathrm{s})$ & Reference \\
\hline $1 a^{a}$ & 0.71 & 364 & $-^{h}$ & $2.7 /-^{h}$ & 49 \\
\hline $1 \mathrm{bb}^{a}$ & 0.52 & 415 & 0.44 & $3.4 / 143$ & 49 \\
\hline $2 \mathbf{a}^{f}$ & 0.08 & 500 & $\begin{array}{l}0.33 \\
(0.53)^{g}\end{array}$ & $12.9 / 2.1$ & 53 \\
\hline $2 \mathbf{2 b}^{f}$ & 0.07 & 495 & $\begin{array}{l}0.20 \\
(0.25)^{g}\end{array}$ & $12.2 / 2.3$ & 53 \\
\hline $2 \mathbf{c}^{f}$ & 0.03 & 540 & 0.02 & $11.4 / 1$ & 53 \\
\hline $3^{c}$ & 0.21 & 420 & 0.42 & $16.7 / 159.9$ & 54 \\
\hline $4^{a}$ & 0.38 & 404 & $\begin{array}{l}0.75 \\
(0.81)^{g}\end{array}$ & $--^{h} /{ }^{h}$ & 56 \\
\hline $5^{a}$ & 0.26 & 420 & $\begin{array}{l}0.30 \\
(0.52)^{g}\end{array}$ & $--^{h} / 70$ & 56 \\
\hline $6 a^{a}$ & 0.39 & 412 & $\begin{array}{l}0.74 \\
(0.77)^{g}\end{array}$ & $-{ }^{h} /-^{h}$ & 56 \\
\hline $\mathbf{6 b}^{a}$ & 0.07 & 475 & $\begin{array}{l}0.05 \\
(0.32)^{g}\end{array}$ & $-{ }^{-h} / 50$ & 56 \\
\hline $7 \mathbf{a}^{b}$ & 0.44 & 408 & 0.80 & $3.9 /-^{h}$ & 57 \\
\hline $7 b^{a}$ & 0.11 & 496 & 0.75 & $-/ 19.2$ & 58 \\
\hline $\mathbf{8}^{b}$ & 0.18 & 442 & 0.06 & $8.7 / 4.5$ & 57 \\
\hline $9^{b}$ & 0.19 & 464 & 0.50 & $14.9 / 15$ & 57 \\
\hline $10 d^{b}$ & 0.664 & 402 & 0.81 & $2.3 /-^{h}$ & 59 \\
\hline $10 \mathrm{e}^{b}$ & 0.063 & 537 & 1.00 & $12 / 5.7$ & 59 \\
\hline $13^{c}$ & 0.27 & 437 & 0.71 & $3.87 / 200$ & 51 \\
\hline $14^{c}$ & 0.34 & 435 & 0.75 & $4.16 / 383$ & 51 \\
\hline $\mathbf{1 5}^{b}$ & 0.06 & 490 & 0.67 & $7.4 / 2.2$ & 60 \\
\hline $16^{b}$ & 0.18 & 462 & 0.40 & $10 / 9.2$ & 60 \\
\hline $17^{b}$ & 0.32 & 451 & 0.67 & $11 / 9.5$ & 60 \\
\hline $18 \mathbf{a}^{c}$ & 0.22 & 460 & 0.86 & $41.9 / 11.1$ & 61 \\
\hline $18 b^{c}$ & 0.24 & 465 & 0.73 & $15.8 / 16.8$ & 61 \\
\hline $19 a^{c}$ & 0.18 & 480 & 0.76 & $36.5 / 6.4$ & 61 \\
\hline $19 \mathbf{b}^{c}$ & 0.18 & 460 & 0.83 & $16.5 / 12.8$ & 61 \\
\hline $20 \mathbf{b}^{c}$ & 0.02 & 500 & 0.60 & $36 / 2.4$ & 52 \\
\hline $21^{e}$ & 0.15 & 450 & 0.73 & $6 / 127$ & 62 \\
\hline
\end{tabular}

${ }^{a}$ Experimental data in $1 \mathrm{wt} \%$ polymethyl methacrylate (PMMA) film ${ }^{b}$ in deoxygenated toluene solution ${ }^{c}$ in $10 \mathrm{wt} \%$ Bis[2-(diphenylphosphino)phenyl]ether oxide (DPEPO) film except $\Delta \mathrm{E}_{\mathrm{ST}}$ in 2-MeTHF glass. ${ }^{d}$ in 5 wt \%_9-(30-(4,6-diphenyl- 1,3,5-triazin-2-yl)-[1,10biphenyl]-3-yl)-9H-carbazole (CzTrz) thin films except $\Delta \mathrm{E}_{\mathrm{ST}}$ in THF. ${ }^{e}$ in $10 \mathrm{wt} \%$ DPEPO film ${ }^{f}$ in neat film except $\Delta \mathrm{E}_{\mathrm{ST}}$ in $\mathrm{mCP}\left(1,3\right.$-Bis $\left(N\right.$-carbazolyl)benzene) ${ }^{g}$ The data in parenthesis correspond to PLQY in vacuum. ${ }^{h}$ No data provided 
Table 2: OLED characteristics of carbazole substituted pyrimidine TADF chromophores

\begin{tabular}{|c|c|c|c|c|c|}
\hline Compds & $\begin{array}{l}\text { EQE }_{\max } \\
(\%)\end{array}$ & $\begin{array}{l}\mathrm{EQE}_{100} \\
(\%)\end{array}$ & $\operatorname{Lum}_{\max }\left(\operatorname{lm} W^{-1}\right)$ & CIE / $\lambda_{\text {EL }}(\mathrm{nm})$ & Reference \\
\hline $1 \mathbf{a}^{a}$ & 8.7 & $-{ }^{i}$ & $-{ }^{i}$ & $(0.16 ; 0.12) / 441$ & 53 \\
\hline $3^{g}$ & 7.5 & 5.7 & 7.1 & $(0.17 ; 0.18) / 458$ & 54 \\
\hline $\mathbf{6 b}^{b}$ & 6.0 & $-^{i}$ & 8.5 & $(0.19 ; 0.29) / 490$ & 56 \\
\hline $7 b^{a}$ & 18.3 & $-i$ & $-{ }^{i}$ & $(0.27 ; 0.49) / 508$ & 58 \\
\hline $9^{c}$ & 19.7 & $-i$ & $-{ }^{i}$ & $(0.16 ; 0.23) / 473$ & 57 \\
\hline $13^{d}$ & 6.2 & $-i$ & 244 & $(0.15 ; 0.054) /-^{i}$ & 51 \\
\hline $14^{d}$ & 5.4 & $-{ }^{i}$ & 233 & $(0.15 ; 0.052) /-^{i}$ & 51 \\
\hline $15^{e}$ & 22.0 & $-{ }_{-i}^{i}$ & $-{ }^{i}$ & $-{ }^{i} / 524$ & 60 \\
\hline $16^{e}$ & 12.7 & $-i$ & $-{ }^{i}$ & $-{ }^{i} / 520$ & 60 \\
\hline $17^{e}$ & 11.9 & $-i$ & $-{ }^{i}$ & $-{ }^{i} / 501$ & 60 \\
\hline $18 \mathbf{a}^{f}$ & 17.1 & $-i$ & 33.1 & $(0.31 ; 0.57) /-^{i}$ & 61 \\
\hline $18 b^{f}$ & 14.5 & $-{ }^{i}$ & 30.2 & $(0.34 ; 0.58) /-^{i}$ & 61 \\
\hline $19 \mathbf{a}^{f}$ & 18.8 & $-{ }^{i}$ & 38.2 & $(0.31 ; 0.56) /-^{i}$ & 61 \\
\hline $19 \mathbf{b}^{f}$ & 19.8 & $-{ }^{i}$ & 41.1 & $(0.33 ; 0.57) /-^{i}$ & 61 \\
\hline $\mathbf{2 0} \mathbf{b}^{f}$ & 17.4 & 16.2 & 30.0 & $(0.35 ; 0.57) / 534$ & 52 \\
\hline $21^{g}$ & 14.0 & 7.0 & $-{ }_{-i}^{i}$ & $(0.19 ; 0.26) / 461$ & 62 \\
\hline
\end{tabular}

${ }^{a}$ Indium tin oxyde (ITO)/ 1,1-Bis[(di-4-tolylamino)phenyl]cyclohexane (TAPC) $(30 \mathrm{~nm}) /$ Tris(4-carbazoyl-9-ylphenyl)amine (TcTa) $(5 \mathrm{~nm}) / 10 \mathrm{wt} \%$ 2:DPEPO $(20 \mathrm{~nm}) / \mathrm{DPEPO}(5$ $\mathrm{nm}) / 1,3,5$-Tris(3-pyridyl-3-phenyl)benzene $(\mathrm{TmPyPb})(50 \mathrm{~nm}) /$ lithium fluoride $(\mathrm{LiF}) \quad(0.8$ $\mathrm{nm}) / \mathrm{Al} \quad(100 \mathrm{~nm}){ }^{b}$ glass/ITO/ 4,4',4"-Tris[phenyl(m-tolyl)amino]triphenylamine $(\mathrm{m}$ MTDATA) $(10 \mathrm{~nm}) / \mathrm{N}, \mathrm{N}^{\prime}$-Bis(naphthalen-1-yl)-N,N'-bis(phenyl)benzidine (NPB) $(15 \mathrm{~nm}) /$ $\mathrm{mCP}(10 \mathrm{~nm}) / 3 \mathrm{wt} \%$ 6:DPEPO $(20 \mathrm{~nm}) / 2,2^{\prime}, 2 "-(1,3,5$-Benzinetriyl)-tris(1-phenyl-1-Hbenzimidazole) $(\mathrm{TPBi})(45 \mathrm{~nm}) / \mathrm{LiF}(0.8 \mathrm{~nm}) / \mathrm{Al}(100 \mathrm{~nm}){ }^{c}$ ITO/TAPC $(30 \mathrm{~nm}) / \mathrm{TcTa}(5$ $\mathrm{nm}) / 10 \mathrm{wt} \%$ emitter: DPEPO $(15 \mathrm{~nm}) / \operatorname{TmPyPB}(65 \mathrm{~nm}) / \operatorname{LiF}(0.8 \mathrm{~nm}) / \mathrm{Al}(100 \mathrm{~nm})^{d}$ ITO/MoO $3(10 \mathrm{~nm}) /$ TAPC $(55 \mathrm{~nm}) / \mathrm{mCP}(10 \mathrm{~nm}) / \mathrm{DPEPO}: 10 \mathrm{wt} \%$ emitters $(25 \mathrm{~nm}) / \mathrm{DPEPO}$ $(10 \mathrm{~nm}) / \mathrm{TmPyPB}(40 \mathrm{~nm}) / \mathrm{LiF}(1 \mathrm{~nm}) / \mathrm{Al}{ }^{e}$ ITO/TAPC $(150 \mathrm{~nm})$ DPEPO: $10 \mathrm{wt} \%$ emitters (30 $\mathrm{nm}) / \mathrm{DPEPO}(5 \mathrm{~nm}) / \operatorname{TmPyPB}(45 \mathrm{~nm}) / \mathrm{LiF}(1 \mathrm{~nm}) / \operatorname{Al}(100 \mathrm{~nm})^{f}$ ITO $(50 \mathrm{~nm}) / \mathrm{N} 4, N 4{ }^{\prime}-B i s[4-$ [bis(3-methylphenyl)amino]phenyl]-N4,N4'-diphenyl-[1,1'-biphenyl]-4,4'-diamine (DNTPD) $(60 \mathrm{~nm}) / \mathrm{N}, \mathrm{N}, \mathrm{N}^{\prime}, \mathrm{N}^{\prime}$-tetrakis(4-biphenylyl)benzidine (BPBPA) $(20 \mathrm{~nm}) /$ 9,10-Dihydro-9,9dimethyl-10- (9-phenyl-9H-carbazol-3-yl)-acridine (PCZAC) $(10 \mathrm{~nm}) / \mathrm{CzTrz}: 10$ wt $\%$ emitters $(30 \mathrm{~nm}) / 2,8$-bis(4,6-diphenyl-1,3,5-triazin-2-yl)dibenzo-[b,d]furan (DBFTrz) $(5 \mathrm{~nm}) /$ 2-[4-(9,10-Di-naphthalen-2-yl-anthracen-2-yl)-phenyl]-1-phenyl-1H-benzoimidazole (ZADN) $\left(30 \mathrm{~nm} / \mathrm{LiF} \quad(1.5 \mathrm{~nm}) / \mathrm{Al} \quad(200 \mathrm{~nm}){ }^{g}\right.$ ITO/ TAPC $(40 \mathrm{~nm}) / \mathrm{mCP} \quad(10 \mathrm{~nm}) / 10 \mathrm{wt} \%$ emitter:DPEPO (30 nm)/DPEPO (10 nm)/TmPyPB (40 nm)/LiF (1 nm)/Al (100 nm $)^{h} \mathrm{ITO} /$ PEDOT:PSS (polystyrene sulfonate) (40 nm)/TAPC $(20 \mathrm{~nm}) / \mathrm{mCP} \quad(10 \mathrm{~nm}) / 10$ wt\% emitter:DPEPO (20 nm)/DPEPO $(10 \mathrm{~nm}) / \mathrm{TmPyPB}(40 \mathrm{~nm}) / \mathrm{LiF}(1 \mathrm{~nm}) / \mathrm{Al}(200 \mathrm{~nm}) i$ no data provided

\section{dihydroacridine (acridan) substituents}

The dihydroacridine fragments, also called acridan, have been extensively used as ED groups in TADF chromophores. ${ }^{66}$ Such acridan fragment encompassing a six-membered central ring increases the spatial encumbrance with the EA fragment when compared to carbazole ED part. $^{40}$ Phenylacridan substituted pyrimidine derivatives are generally obtained either by Buchwald-Hartwig amination reaction of halogeno phenylpyrimidine derivatives with the corresponding acridan fragment ${ }^{67}$ or by Suzuki cross-coupling reaction of chloropyrimidines with boronic acid/ester of phenylacridan. ${ }^{68}$ 
Nakao et al and Ganesan and coworkers have studied independently the TADF properties of 9,9-dimethyl-9,10-dihydroacridine derivatives 22 and 23 (Chart 9). ${ }^{42,67}$ As already observed, the presence of the ED group at the $\mathrm{C} 4$ position (compound 23a) instead of $\mathrm{C} 2$ position (compound 22a) is beneficial for the reduction of $\Delta \mathrm{E}_{\mathrm{ST}}$ and increases the PLQY (Table 3). As also expected, the emission of chromophores 23a and 23c is red-shifted with respect to compounds 22a and 22b respectively, either in solution or in thin films. The presence of a methyl group in the structure of dyes $\mathbf{2 2 b}$ and $\mathbf{2 3 c}$ triggers a slightly blue-shifted emission and a large increase of their PLQY without modifying significantly $\Delta \mathrm{E}_{\mathrm{ST}}$ nor delayed fluorescence lifetimes. Compounds 22a, 22b, 23a and 23c have also been investigated in a recent theoretical work by Zhu et al. ${ }^{69}$ Using a semi-classical approach and TD-DFT, they estimated both the SOC and $\Delta \mathrm{E}_{\mathrm{ST}}$, granting access to the theoretical reverse intersystem crossing rate constant, $\mathrm{k}_{\mathrm{RISC}}$. Calculated $\mathrm{k}_{\mathrm{RISC}}$ are in good agreement with the experimental measurements, ranging from $1.22 \times 10^{5} \mathrm{~s}^{-1}$ for 22b to $2.30 \times 10^{6} \mathrm{~s}^{-1}$ for 23a. More specifically, it has been rationalized that the symmetry of the pyrimidine core in $\mathbf{2 2}$ (symmetrical) and $\mathbf{2 3}$ (unsymmetrical) modifies the nature of excited states. Notably, whereas for $\mathbf{2 2}$ the $\mathrm{T}_{1}$ state has a predominant LE character, it has a remarkable CT character in 23. Combined to the dominant $\mathrm{CT}$ nature of the $\mathrm{S}_{1}$, the theoretical $\Delta \mathrm{E}_{\mathrm{ST}}$ is reduced, leading to faster RISC. Besides, the presence of carbazole ED groups on the acridine fragment in the structure of compound 23b induces a reduction of $\Delta \mathrm{E}_{\mathrm{ST}}{ }^{67}$ Sky blue and blue emitting OLED were obtained with compounds 22 and $\mathbf{2 3}$, respectively. In case of blue emitting compound $\mathbf{2 3 b}$, an $\mathrm{EQE}_{\max }$ close to $25 \%$ has been achieved (Table 4 ).<smiles>[R]c1ccccc1-c1cc(-c2ccccc2)nc(-c2ccc(N3c4ccccc4C(C)(C)c4ccccc43)cc2)n1</smiles>

22a $R^{1}=H$ 22b $R^{1}=M e$<smiles>[R]c1ccc2c(c1)C(C)(C)c1cc([R])ccc1N2c1ccc(-c2cc(-c3ccccc3)nc(-c3ccccc3[R])n2)cc1</smiles>

$$
\begin{aligned}
& \text { 23a } R^{1}=R^{2}=H \\
& \text { 23b } R^{1}=H, R^{2}=\text { carbazol-9-yl } \\
& \text { 23c } R^{1}=M e, R^{2}=H
\end{aligned}
$$

Chart 9. Structure of 9,9-dimethyl-9,10-dihydroacridine-substituted pyrimidine chromophores 22 and $\mathbf{2 3}$

Fecková and coworkers designed 9,9-dimethyl-9,10-dihydroacridine-substituted pyrimidine chromophores 24 and 25 (Chart 10). ${ }^{68}$ In these structures, the HOMO is computed to be isolated on the out-of-plane acridan part. However, no delayed emission was observed for these compounds, neither in solution nor in thin films. For methoxy derivatives, dual emission was observed in solid state and in some solvents of moderate polarity with an emission band of higher energy attributed to an excited state with LE character and a second one having an ICT nature. Nevertheless, both bands exhibit lifetimes too short to be attributed to TADF ( $\tau<$ $10 \mathrm{~ns}$ ). The anticipated TADF behavior was not observed, probably because the HOMO $\rightarrow$ LUMO transition did not possess any oscillator strength as shown by TD-DFT calculations. 


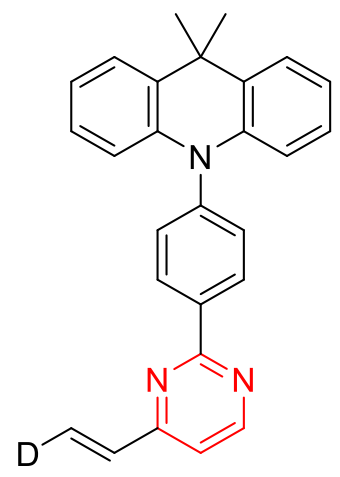

24

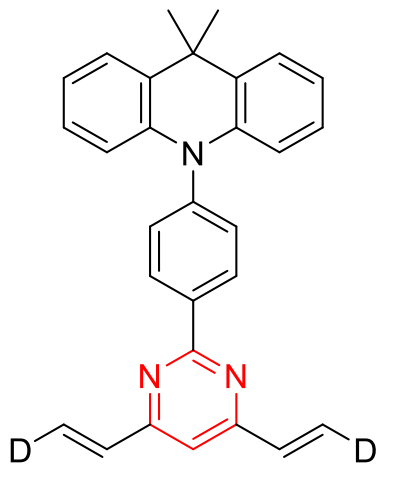

25
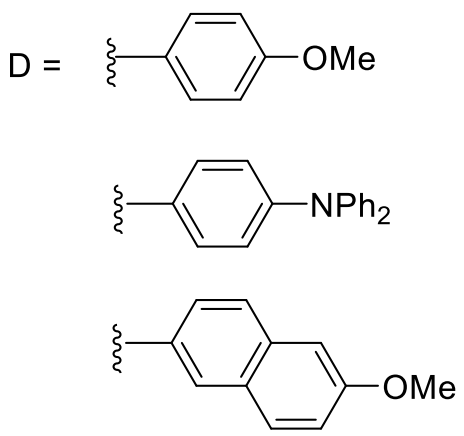

Chart 10. Structure of arylvinylpyrimidine chromophores 24 and 25

Pyrimidine chromophores bearing two 9,9-dimethyl-9,10-dihydroacridine were also proposed (Chart 11). In the structure of compounds 26, designed by Komatsu et al, the acridan fragments are located in $\mathrm{C} 4$ and $\mathrm{C} 6$ position of the pyrimidine core (Figure 2) ${ }^{70,71}$ All compounds of this series exhibit delayed fluorescence in doped DPEPO films and the nature of the substituent in $\mathrm{C} 2$ position does not modify significantly the TADF properties, even if a small blue shift is observed in the case of compound 26c with a methyl substituent. When comparing compound 26b with analogue 23a bearing only one acridan substituent, the second acridan moiety triggers a $21 \mathrm{~nm}(0.11 \mathrm{eV})$ red shift of emission maxima and a four-fold reduction of the lifetime of delayed fluorescence (from $87 \mu \mathrm{s}$ to $21 \mu \mathrm{s}$ ). The presence of methyl groups in C5 position of the pyrimidine ring (compound 26d) or in the phenyl substituent (compound 26e) leads to a blue shift of emission related to the reduction of $\pi$ conjugation within the molecular backbone due to steric hindrance. This is more noticeable when a methyl group is present in both the C5 position of pyrimidine and on the phenyl fragments (compound 26f). However, no reduction of $\Delta \mathrm{E}_{\mathrm{ST}}$ is observed with this strategy, rather $\Delta \mathrm{E}_{\mathrm{ST}}$ increases. An optimized OLED with compound 26c inserted in a DPEPO matrix $(10 \mathrm{wt} \%)$ led to a light blue emitting OLED with $\mathrm{EQE}_{\max }$ close to $25 \%$. Lee and coworkers designed linear C2 and C5 di-substituted pyrimidine chromophore 27. ${ }^{72}$ According to DFT calculations, the 9,9-dimethyl-9,10-dihydroacridine groups are both almost perpendicular to the phenyl linkers with dihedral angles of $89.5^{\circ}$ and $89.8^{\circ}$, respectively. The predicted $\Delta \mathrm{E}_{\mathrm{ST}}$ in the gas phase is almost vanishing $(0.01 \mathrm{eV})$. In line with these findings, TADF was observed with a particularly long delayed fluorescence lifetime of $486 \mu$ s. Differences in the OLED architectures fabricated with emitters 23a and 27 prevents a fair comparison to be made between the efficiency of these emitters. Still, the overall performances of emitters 23a appear superior, indicating that the $\mathrm{C} 4$ and $\mathrm{C} 6$ di-substitution of the pyrimidine ring tends to be more favorable than $\mathrm{C} 2$ and $\mathrm{C} 5$ for TADF OLED applications.

Serevičius et al developed the thiomethylpyrimidine derivative $\mathbf{2 8}$ bearing two 9,9-dimethyl9,10-dihydroacridine units directly connected to the pyrimidine core in C4 and C6 position (Chart 11). ${ }^{73}$ Optimization of these sterically confined molecular structures aimed at minimizing the conformational disorder, and thus the dispersion of $\Delta \mathrm{E}_{\mathrm{ST}}$, so as to ensure efficient triplet upconversion in the solid state. Ground-state DFT geometry optimization revealed that the plans of the two acridan units are nearly orthogonal with respect to the central pyrimidine core, having dihedral angles close to $87^{\circ}$, and quasi-axial orientations of the acridine units are hindered by the methyl group in $\mathrm{C} 5$ position of the pyrimidine. This compound exhibits delayed fluorescence in diphenyl[4-(triphenylsilyl)phenyl]phosphine oxide (TSPO1) matrix with rather high PLQY (67\%) and a relatively short delayed fluorescence lifetime of $1.76 \mu \mathrm{s}$. Combining temperature dependent time-resolved 
fluorescence experiments with DFT calculations allowed to demonstrate the role of an intermediate triplet state that leads to efficient ISC/RISC through spin-vibronic coupling. Sky blue emission of this emitter in an OLED with rather high efficiency $\left(\mathrm{EQE}_{\max }=14.3 \%\right)$ and minor roll-off was reported.

Wang and coworkers designed the triphenylpyrimidine 29 (Chart 11) ${ }^{74}$ In this structure, two acridan substituents are positioned at the meta position of C6 phenyl unit (Figure 2). HOMO and LUMO, respectively distributed on the acridan and pyrimidine part, are significantly separated. The $\Delta \mathrm{E}_{\mathrm{ST}}$ experimentally estimated in toluene amounts to $0.03 \mathrm{eV}$ and in thin filmss a delayed emission with a lifetime of $14 \mu \mathrm{s}$ is observed. A blue green OLED based on dye 29 as emitter with a maximum efficiency of $13 \%$ was demonstrated. Furthermore, a bluehazard-free hybrid WOLED using 29 as both host and emitter with $\mathrm{EQE}_{\max }$ of $15.6 \%$ was achieved.<smiles></smiles>

$$
\begin{aligned}
& \text { 26a } R^{1}=R^{2}=R^{3}=H \\
& \text { 26b } R^{1}=P h, R^{2}=R^{3}=H \\
& \text { 26c } R^{1}=M e, R^{2}=R^{3}=H \\
& \text { 26d } R^{1}=R^{3}=H, R^{2}=M e \\
& \text { 26e } R^{1}=R^{2}=H, R^{3}=M e \\
& \text { 26f } R^{1}=H, R^{2}=R^{3}=M e
\end{aligned}
$$<smiles>CC1(C)c2ccccc2N(c2ccc(-c3cnc(-c4ccc(N5c6ccccc6C(C)(C)c6ccccc65)cc4)nc3)cc2)c2ccccc21</smiles><smiles>Cc1nc(N2c3ccccc3C(C)(C)c3ccccc32)c(C)c(N2c3ccccc3C(C)(C)c3ccccc32)n1</smiles>

28<smiles>C=CCN(CC=C)c1cc(-c2cc(-c3ccc(-c4ccccc4)cc3)nc(-c3ccccc3)n2)cc(N2c3ccccc3C(C)(C)c3ccccc32)c1</smiles>

29

Chart 11. Structure of 9,9-dimethyl-9,10-dihydroacridine-disubstituted pyrimidine chromophores 26-29

Yasuda and coworkers have designed the 2-substituted pyrimidine chromophores 30-32 with various acridan fragments (Chart 12). ${ }^{75}$ X-ray structure of compound $\mathbf{3 1 b}$ indicates a dihedral angle between the spiroacridan fragment and the phenylene linker of $80^{\circ}$. All compounds exhibit delayed fluorescence in doped thin filmss. The replacement of the dimethylacridan fragment in the structure of $\mathbf{3 0}$ by fluorene or xanthene spiroacridan groups (chromophores $\mathbf{3 1}$ and 32 respectively) leads to a moderate reduction of $\Delta \mathrm{E}_{\mathrm{ST}}$ and a reduction of delayed emission lifetimes. Sky blue emitting OLEDwere obtained with all compounds with an increase of $\mathrm{EQE}_{\max }$ and $\mathrm{Lum}_{\max }$ with the spiroacridan fragments, more pronounced for the 
fluorene spiroacridan derivatives 31, 31b achieving an $\mathrm{EQE}_{\max }$ over $20 \%$ and a $\mathrm{Lum}_{\max }$ over $37 \mathrm{~lm} \mathrm{~W} \mathrm{~W}^{-1}$.

Monkman, Bryce and coworkers have designed a series of chromophores to study the impact of bulky adamantyl groups, which induce steric interactions but are optically and electronically innocent, on the TADF properties of spiroacridan substituted pyrimidine chromophores 33 (Chart 12). ${ }^{76}$ TD-DFT calculations reveal that the adamantyl groups (compounds 33b-c) change molecular dynamic modes within the molecule, and in turn the vibronic coupling between singlet or triplet states relevant to ISC/RISC and TADF. Dispersion in Zeonex polymer films and in solution shows that the presence of the adamantyl moiety in the electronically identical compounds (33b versus 33a) hardly affects $\Delta \mathrm{E}_{\mathrm{ST}}$ but significantly changes the delayed emission. The massive adamantyl groups hinder rotation/rocking about the ED-EA N-C bond, which reduces the vibronic coupling between singlet and triplet states that mediates RISC and in turn increases the direct emission from the triplet. Additional adamantyl substitution on the EA pyrimidine moiety alters its electronic system which leads to larger $\triangle \mathrm{E}_{\mathrm{ST}}$ and lower PLQY. Still all three compounds exhibit strong TADF in solution (DCM or o-DCB) with 33c lagging behind in terms of RISC and ISC, indicating that vibronic coupling from other low-amplitudes vibrational modes may also contribute. This work clearly stresses the complexity of the vibrational coupling mechanism and prompts further investigations based on the insertion of electronically innocent bulky groups.
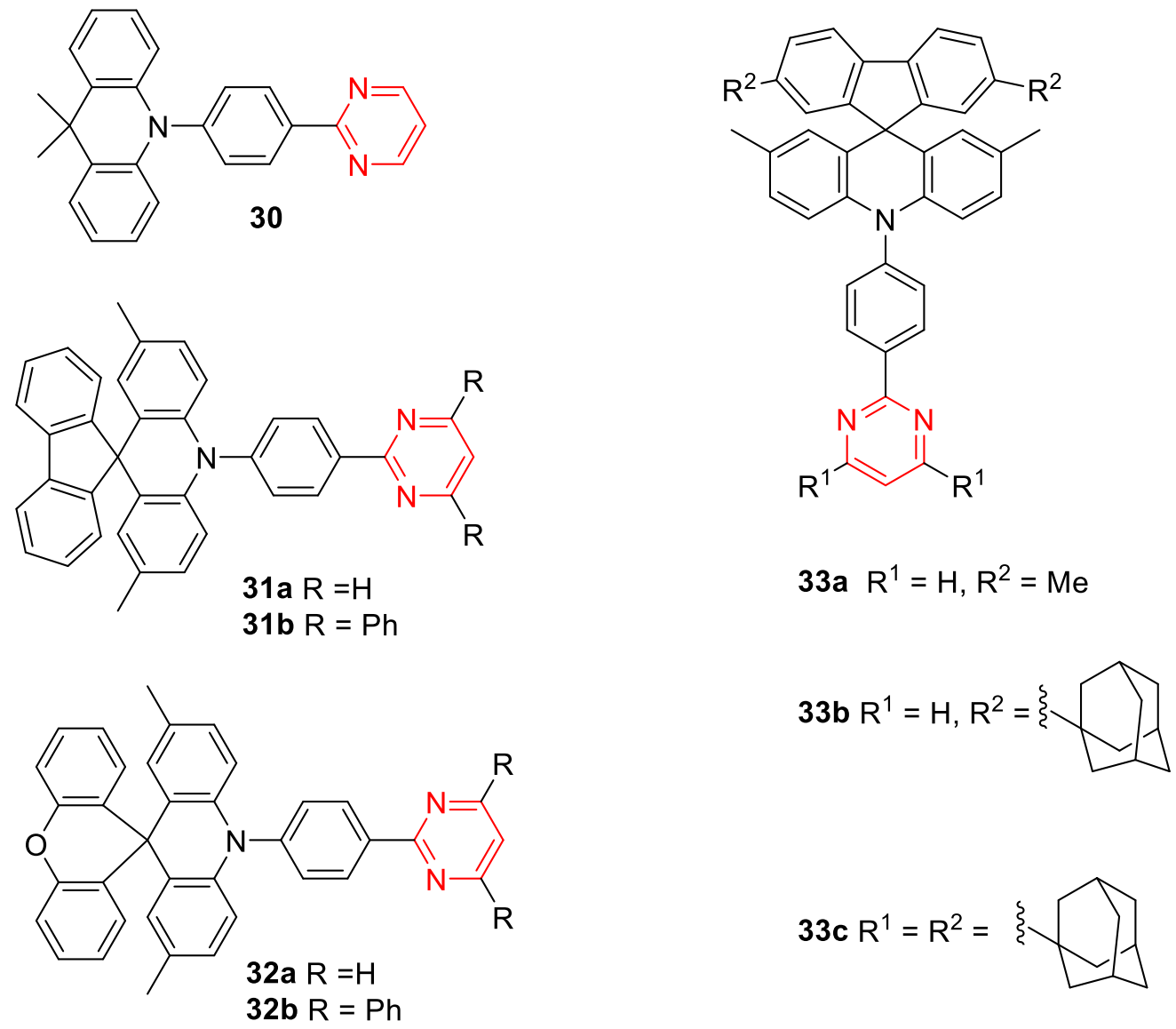

Chart 12. Structure of 2-phenylpyrimidine chromophores 30-33.

Yasuda, Zhang and Wang have designed two series of 4,6-disubstituted pyrimidine derivatives with diphenylacridan and fluorene spiroacridan ED fragments (compounds $\mathbf{3 4}$ and 35 respectively, Chart 13) ${ }^{77,78}$ The nature of the $\mathrm{C} 2$ substituent $(\mathrm{H}, \mathrm{Me}$ or $\mathrm{Ph})$ does not change 
significantly their photophysical properties and all compounds show high PLQY. The fluorene spiroacridan ED provides sizeably lower $\Delta \mathrm{E}_{\mathrm{ST}}$ and delayed fluorescence lifetimes. Highly efficient sky-blue emitting OLEDwere obtained with both series of compounds, with a record $\mathrm{EQE}_{\max }$ value of $30.5 \%$ with the emitter $\mathbf{3 5 b}$. Unfortunately, it is not possible to compare the TADF properties of these emitters with dimethylacridan analogues 26a-c, as the data were not measured in the same matrix.

Bispyrimidine derivative 36 bearing a spirobisacridan central core was designed by Sasabe, Su and Kido (Chart 13). ${ }^{79}$ This sticklike compound is inclined to lie parallel to the substrate in vacuum-deposited thin solid films. This allowed to achieve a sky-blue emitting OLED with $\mathrm{EQE}_{\max }$ close to $30 \%$. Besides, the chromophore 36 exhibits a blue-shifted emission with respect to its triazine analogue that affords a greenish-blue devices with an $\mathrm{EQE}_{\max }$ over $35 \%$.<smiles>[R]c1nc(-c2ccc(N3c4ccccc4C(c4ccccc4)(c4ccccc4)c4ccccc43)cc2)cc(-c2ccc(N3c4ccccc4C(c4ccccc4)(c4ccccc4)c4ccccc43)cc2)n1</smiles><smiles>[R]c1nc(-c2ccc(N3c4ccccc4C4(c5ccccc5-c5ccccc54)c4ccccc43)cc2)cc(-c2ccc(N3c4ccccc4C4(c5ccccc5-c5ccccc54)c4ccccc43)cc2)n1</smiles><smiles>c1ccc(-c2cc(-c3ccccc3)nc(-c3ccccc3)n2)cc1</smiles>

Chart 13. Structure of acridan substituted pyrimidine chromophores 34-36.

Lee, Wang et al have designed a series of regioisomers of acridan-carbazole hybrid ED substituted pyrimidine chromophores 37 (Chart 14). ${ }^{43,80}$ There is a strong influence of the position of the carbazole. In the case of compound 37a, the large steric hindrance between the donor and acceptor part induces a relatively planar quasi-axial (QA) conformation which prevents TADF properties. On the other hand, regioisomers 37b-c show an orthogonal quasiequatorial $(\mathrm{QE})$ conformation with red-shifted emission and notable TADF characteristics. These chromophores revealed to be efficient blue-green emitters and for low dopant concentration 37b lead to an OLED with $\mathrm{EQE}_{\max }$ over $28 \%$.

Kaji et al designed chromophore 38, starting from its phenyl analogue and substituting two phenyl groups with pyrimidine fragments (Chart 15) so as to modulate the nature of the $S_{1}$ and $\mathrm{T}_{1}$ states. ${ }^{81}$ Based on TD-DFT calculations they predict that the $\mathrm{S}_{1}, \mathrm{~S}_{2}, \mathrm{~T}_{1}$ and $\mathrm{T}_{2}$ states are nearly degenerated and that all have an important but non-identical CT character. This ensures not only small $\Delta \mathrm{E}_{\mathrm{ST}}$ but also non-zero SOC values, according to the El-Sayed rule ${ }^{82}$. In line with the theoretical prediction, the experimental $\mathrm{k}_{\mathrm{RISC}}$ in toluene of $\mathbf{3 8}\left(8.810^{5} \mathrm{~s}^{-1}\right)$ is three times larger than that of its phenyl analogue, and this compound is thus a promising candidate for TADF. 
<smiles>[R]c1ccc(-c2cc(C([In])[Tl])nc(-c3ccccc3)n2)cc1</smiles><smiles>[R]=[Ni]N1c2ccccc2C(C)(C)c2ccc3c(c21)c1ccccc1n3-c1ccccc1</smiles><smiles>CCN1c2ccccc2C(C)(C)c2cc3c4ccccc4n(-c4ccccc4)c3cc21</smiles><smiles>CN1c2ccccc2C(C)(C)c2c1ccc1c2c2ccccc2n1-c1ccccc1</smiles>

Chart 14. Structure of acridan carbazole derivatives 37<smiles>CC1(C)c2ccccc2N(c2ccc(-c3nc(-c4ncccn4)nc(-c4ncccn4)n3)cc2)c2ccccc21</smiles>

Chart 15. Structure of triazine derivative $\mathbf{3 8}$ 
Table 3: Photophysical data of acridan substituted pyrimidine TADF chromophores

\begin{tabular}{|c|c|c|c|c|c|}
\hline Compds & $\Delta E_{S T}(e V)$ & $\lambda_{\mathrm{em}}(\mathrm{nm})$ & PLQY & $\tau_{\mathrm{PF}}(\mathbf{n s}) / \tau_{\mathrm{DF}}(\mu \mathbf{s})$ & Reference \\
\hline $10 \mathbf{a}^{a}$ & 0.251 & 483 & 0.82 & $16 /-^{l}$ & 59 \\
\hline $11 a^{a}$ & 0.114 & 531 & 0.80 & $21 / 2.0$ & 59 \\
\hline $12 \mathbf{a}^{a}$ & 0.336 & 452 & 0.50 & $6.7 /-^{l}$ & 59 \\
\hline $22 \mathbf{a}^{b}$ & 0.25 & 404 & 0.61 & $-1 / 178$ & 67 \\
\hline $22 \mathbf{a}^{c}$ & 0.11 & 525 & 0.63 & $18.2 / 16.5$ & 42 \\
\hline $22 \mathbf{b}^{c}$ & 0.13 & 517 & 0.80 & $24.3 / 24.5$ & 42 \\
\hline $23 \mathbf{a}^{b}$ & 0.17 & 477 & 0.81 & $-1 / 87$ & 67 \\
\hline $23 a^{c}$ & 0.08 & 566 & 0.43 & $25.0 / 2.52$ & 42 \\
\hline $23 \mathbf{b}^{b}$ & 0.12 & 421 & 0.81 & $-1 / 55$ & 67 \\
\hline $23 c^{c}$ & 0.08 & 558 & 0.88 & $2.7 / 3.79$ & 42 \\
\hline $26 \mathbf{a}^{b}$ & 0.18 & 498 & 0.77 & $-1 / 21.4$ & 70 \\
\hline $26 \mathbf{b}^{b}$ & 0.19 & 498 & 0.79 & $-1 / 20.7$ & 70 \\
\hline $26 c^{b}$ & 0.19 & 489 & 0.80 & $-1 / 26.2$ & 70 \\
\hline $\mathbf{2 6 d}^{d}$ & 0.23 & 477 & 0.75 & $-1 / 50.3$ & 71 \\
\hline $26 \mathbf{e}^{d}$ & 0.22 & 477 & 0.71 & $-l / 44.0$ & 71 \\
\hline $26 f^{d}$ & 0.24 & 454 & 0.47 & $-1 / 45.2$ & 71 \\
\hline $27^{c}$ & -1 & 477 & 0.53 & $19 / 486$ & 72 \\
\hline $28^{e}$ & 0.03 & 475 & 0.67 & $26.6 / 1.76$ & 73 \\
\hline $29^{a}$ & 0.03 & 496 & -1 & $43^{f} / 14^{f}$ & 74 \\
\hline 30 $^{g}$ & 0.30 & 457 & 0.83 & $11 / 78$ & 75 \\
\hline $31 a^{g}$ & 0.26 & 466 & 0.91 & $13 / 45$ & 75 \\
\hline $31 b^{g}$ & 0.25 & 464 & 0.87 & $12 / 38$ & 75 \\
\hline $32 \mathbf{a}^{g}$ & 0.29 & 458 & 0.90 & $11 / 70$ & 75 \\
\hline $32 b^{g}$ & 0.25 & 452 & 0.69 & $11 / 40$ & 75 \\
\hline $33 \mathbf{a}^{h}$ & 0.19 & 452 & 0.71 & $6 / 3300$ & 76 \\
\hline $33 b^{h}$ & 0.20 & 452 & 0.66 & $7.3 / 2400$ & 76 \\
\hline $33 c^{h}$ & 0.30 & 441 & 0.38 & $4.4 / 1200$ & 76 \\
\hline 34a $\mathbf{a}^{g}$ & 0.26 & 458 & 0.92 & $11 / 330$ & 77 \\
\hline $34 b^{g}$ & 0.24 & 462 & 0.94 & $11 / 210$ & 77 \\
\hline $35 \mathbf{a}^{b, i}$ & 0.19 & 461 & 0.82 & $13 / 54$ & 78 \\
\hline $35 \mathbf{b}^{b, i}$ & 0.16 & 464 & 0.97 & $17 / 56$ & 78 \\
\hline $35 c^{b, i}$ & 0.15 & 469 & 0.97 & $17 / 52$ & 78 \\
\hline $\mathbf{3 6}^{b, j}$ & 0.07 & 471 & 0.73 & $-1 / 231$ & 79 \\
\hline $37 \mathbf{a}^{b}$ & 0.39 & 440 & 0.78 & $10 /-^{\prime}$ & 80 \\
\hline $37 \mathbf{b}^{b}$ & 0.06 & 516 & 0.95 & $14 / 3.4$ & 80 \\
\hline $37 c^{k}$ & 0.15 & 520 & 0.88 & $67 / 0.73$ & 43 \\
\hline
\end{tabular}

${ }^{a}$ in deoxygenated toluene solution ${ }^{b}$ in $10 \mathrm{wt} \%$ DPEPO film ${ }^{c}$ in $6 \mathrm{wt} \%$ Polythienothiophene (PTT) film ${ }^{d}$ in $20 \mathrm{wt} \%$ DPEPO film ${ }^{e}$ in $3 \mathrm{wt} \%$ TSPO1 film ${ }^{f}$ in thin films ${ }^{g}$ in $18 \mathrm{wt} \% 2,8-$ Bis(diphenylphosphineoxide)-dibenzofuran (PPF) film ${ }^{h}$ in $5 \mathrm{wt} \%$ zeonex film. ${ }^{i} \Delta \mathrm{E}_{\mathrm{ST}}$ and $\lambda_{\text {em }}$ in toluene; ${ }^{j} \Delta \mathrm{E}_{\mathrm{ST}}$ in toluene ${ }^{k}$ in $10 \%{ }^{4,4^{\prime}}$-di(9H-carbazol-9-yl)-1, $1^{\prime}$-biphenyl (CBP) film ${ }^{l}$ no data provided. 
Table 4: OLED characteristics of acridan substituted pyrimidine TADF chromophores

\begin{tabular}{|c|c|c|c|c|c|}
\hline Compds & $\begin{array}{l}\text { EQE }_{\max } \\
(\%)\end{array}$ & $\begin{array}{l}\mathrm{EQE}_{100} \\
(\%)\end{array}$ & $\begin{array}{l}\operatorname{Lum}_{\max } \\
\left(\operatorname{lmW}^{-1}\right)\end{array}$ & CIE / $\lambda_{\text {EL }}(\mathrm{nm})$ & Reference \\
\hline $22 \mathbf{a}^{a}$ & 15.5 & 4.5 & 19.7 & $(0.16 ; 0.21) /-^{m}$ & 67 \\
\hline $23 \mathbf{a}^{a}$ & 19.3 & 11.9 & 43.5 & $(0.18 ; 0.33) /-^{m}$ & 67 \\
\hline $23 b^{a}$ & 23.7 & 14.9 & 59.2 & $(0.21 ; 0.38) /-^{m}$ & 67 \\
\hline $26 \mathbf{a}^{b}$ & 20.9 & 17.6 & 60.3 & $(0.21 ; 0.44) /-^{m}$ & 70 \\
\hline $26 b^{b}$ & 19.0 & 16.6 & 52.8 & $(0.21 ; 0.44) /-^{m}$ & 70 \\
\hline $26 c^{b}$ & 20.4 & 16.1 & 49.9 & $(0.19 ; 0.37) /-^{m}$ & 70 \\
\hline $26 c^{c}$ & 24.5 & 17.2 & 61.6 & $(0.19 ; 0.37) /-^{m}$ & 70 \\
\hline 26d $\mathbf{d}^{d}$ & 24.0 & 19.0 & 45.1 & $(0.17 ; 0.28) /-^{m}$ & 70 \\
\hline $26 \mathbf{e}^{d}$ & 19.8 & 15.9 & 35.8 & $(0.17 ; 0.27) /-^{m}$ & 71 \\
\hline $26 f^{d}$ & 17.8 & 10.4 & 19.6 & $(0.16 ; 0.15) /-^{m}$ & 71 \\
\hline $27^{e}$ & 11.9 & $-{ }^{m}$ & 25.0 & $(0.17: 0.32) / 487$ & 72 \\
\hline $\mathbf{2 8}^{f}$ & 14.5 & $-{ }^{m}$ & $-{ }^{m}$ & $(0.17 ; 0.27) /-^{m}$ & 73 \\
\hline $29^{g}$ & 13.0 & 10.3 & 35 & $(0.24 ; 0.38) /-^{m}$ & 74 \\
\hline $30^{h}$ & 11.4 & 5.4 & 16.5 & $(0.15 ; 0.15) / 458$ & 75 \\
\hline $31 a^{h}$ & 17.1 & 10.9 & 31.7 & $(0.16 ; 0.21) / 469$ & 75 \\
\hline $\mathbf{3 1 b}^{h}$ & 20.4 & 13.6 & 37.2 & $(0.16 ; 0.23) / 470$ & 75 \\
\hline $32 a^{h}$ & 14.3 & 8.4 & 20.7 & $(0.16 ; 0.19) / 460$ & 75 \\
\hline $32 \mathbf{b}^{h}$ & 12.2 & 8.2 & 18.8 & $(0.16 ; 0.20) / 462$ & 75 \\
\hline $34 \mathbf{a}^{h}$ & 19.0 & 9.4 & 27.9 & $(0.16 ; 0.21) / 468$ & 77 \\
\hline $34 b^{h}$ & 20.8 & 12.4 & 31.5 & $(0.16 ; 0.24) / 472$ & 77 \\
\hline 35a ${ }^{i}$ & 24.3 & 16.1 & 42.4 & $(0.17 ; 0.29) /-^{m}$ & 78 \\
\hline $35 \mathbf{b}^{i}$ & 31.4 & 18.3 & 56.8 & $(0.18 ; 0.32) /-^{m}$ & 78 \\
\hline $35 c^{i}$ & 25.5 & 18.9 & 51.6 & $(0.18 ; 0.34) /-^{m}$ & 78 \\
\hline $36^{j}$ & 29.2 & 21.0 & 27.5 & $(0.17 ; 0.28) /-^{m}$ & 79 \\
\hline $37 \mathbf{a}^{k}$ & 5.7 & 3.4 & 1.9 & $(0.15 ; 0.05) / 433$ & 80 \\
\hline $37 b^{k}$ & 28.4 & 19.3 & 66.5 & $(0.21 ; 0.47) / 499$ & 80 \\
\hline $37 \mathrm{c}^{l}$ & 22.6 & 22.0 & 72.4 & $(0.33 ; 0.58) / 520$ & 43 \\
\hline
\end{tabular}

${ }^{a}$ ITO/TAPC $(20 \mathrm{~nm}) / 10 \mathrm{wt} \% \mathrm{mCBP}(10 \mathrm{~nm}) / 10 \mathrm{wt} \%$ emitter-doped DPEPO $(10 \mathrm{~nm}) / 1,3-B$ is $(3,5-$ dipyrid-3-ylphenyl)benzene (B3PyPB) $(50 \mathrm{~nm}) / \mathrm{LiF}(0.5 \mathrm{~nm}) / \mathrm{Al}(100 \mathrm{~nm}){ }^{b}$ ITO/TAPC $(30 \mathrm{~nm}) / 10$ wt $\%$ emitter:DPEPO $(20 \mathrm{~nm}) / \mathrm{B} 3$ PyPB $(50 \mathrm{~nm}) / \mathrm{LiF}(0.5 \mathrm{~nm}) / \mathrm{Al}(100 \mathrm{~nm}){ }^{b}$ ITO/TAPC $(30 \mathrm{~nm}) / 10$ wt $\%$ emitter:DPEPO $(20 \mathrm{~nm}) / \mathrm{B} 3$ PyPB $(50 \mathrm{~nm}) / \mathrm{LiF}(0.5 \mathrm{~nm}) / \mathrm{Al}(100 \mathrm{~nm}){ }^{c}$ ITO/TAPC $(30 \mathrm{~nm}) / 10$ wt $\%$ 23c-doped mCP $(10 \mathrm{~nm}) / 10 \mathrm{wt} \%$ 23c-doped DPEPO $(10 \mathrm{~nm}) / \mathrm{B} 3 \mathrm{PyPB}(50 \mathrm{~nm}) / \mathrm{LiF}(0.5 \mathrm{~nm}) / \mathrm{Al}$ $(100 \mathrm{~nm}){ }^{d}$ ITO/PPBI $(20 \mathrm{~nm}) /$ TAPC $(20 \mathrm{~nm}) / 20 \mathrm{wt} \%$ emitter-doped DPEPO $(20 \mathrm{~nm}) /$ DPEPO (10

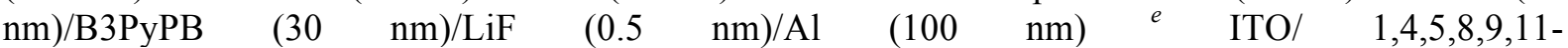
Hexaazatriphenylenehexacarbonitrile (HATCN) $(10 \mathrm{~nm}) / \mathrm{N}, \mathrm{N}^{\prime}-\mathrm{Di}(1$-naphthyl)-N,N'-diphenyl-(1,1'biphenyl)-4,4'-diamine ( $\alpha$-NPD) $(30 \mathrm{~nm}) / \mathrm{mCP}(5 \mathrm{~nm}) / 6 \mathrm{wt} \%$ emitter-doped PPT(30 nm)/ TPBi $(40$ $\mathrm{nm}) / \mathrm{LiF}(0.8 \mathrm{~nm}) / \mathrm{Al}(80 \mathrm{~nm}){ }^{f}$ ITO/TAPC $(30 \mathrm{~nm}) / 10 \mathrm{wt} \% \mathbf{2 3 c}$-doped $\mathrm{mCP}(10 \mathrm{~nm}) / 10 \mathrm{wt} \% \mathbf{2 3 c}$ doped DPEPO $(10 \mathrm{~nm}) / \mathrm{B} 3$ PyPB $(50 \mathrm{~nm}) / \mathrm{LiF}(0.5 \mathrm{~nm}) / \mathrm{Al}(100 \mathrm{~nm}){ }^{f}$ ITO $(125 \mathrm{~nm}) /$ TAPC $(20 \mathrm{~nm}) /$ $\mathrm{mCP}(10 \mathrm{~nm}) / 10 \mathrm{wt} \%$ emitter-doped TSPO1 $(20 \mathrm{~nm}) / \mathrm{TmPyPB}(45 \mathrm{~nm}) / \mathrm{LiF}(0.8 \mathrm{~nm}) / \mathrm{Al}(100 \mathrm{~nm})^{g}$ ITO/ $/ \mathrm{MoO}_{3}(3 \mathrm{~nm}) / \mathrm{TAPC}(30 \mathrm{~nm}) / \mathrm{TcTa}(5 \mathrm{~nm}) / \mathrm{TcTa}: 20 \mathrm{wt} \% \mathbf{2 6}(20 \mathrm{~nm}) / \mathrm{TmPyPB}(50 \mathrm{~nm}) / \mathrm{LiF}(0.5$ $\mathrm{nm}) / \mathrm{Mg}: \mathrm{Ag}(120 \mathrm{~nm}){ }^{h}$ ITO/HATCN $(10 \mathrm{~nm}) / \alpha-\mathrm{NPD}(40 \mathrm{~nm}) / \mathrm{CCP}(5 \mathrm{~nm}) / 18 \mathrm{wt} \%$-emitter:PPF $(20$ $\mathrm{nm}) / \mathrm{PPF}(10 \mathrm{~nm}) / \mathrm{TPBi}(30 \mathrm{~nm}) / \mathrm{Liq}(1 \mathrm{~nm}) / \mathrm{Al}(100 \mathrm{~nm})^{i}$ ITO/HATCN $(5 \mathrm{~nm}) / \mathrm{TAPC}(30 \mathrm{~nm}) / \mathrm{mCP}$ $(10 \mathrm{~nm}) / 10 \mathrm{wt} \%$-emitter:DPEPO $(20 \mathrm{~nm}) / \mathrm{DPEPO}(5 \mathrm{~nm}) / \mathrm{TPBi}(40 \mathrm{~nm}) / \mathrm{LiF}(0.9 \mathrm{~nm}) / \mathrm{Al}(100 \mathrm{~nm})^{j}$ ITO/TAPC $(20 \mathrm{~nm}) / \mathrm{mCP}(10 \mathrm{~nm}) / 10 \mathrm{wt} \%$-emitter:DPEPO $(20 \mathrm{~nm}) / \mathrm{DPEPO}(10 \mathrm{~nm}) / \mathrm{B} 3 \mathrm{PyPB}(40$ $\mathrm{nm}) / \mathrm{LiF}(0.5 \mathrm{~nm}) / \mathrm{Al}(100 \mathrm{~nm}){ }^{h}$ ITO/PEDOT :PSS $(60 \mathrm{~nm}) / \mathrm{TAPC}(20 \mathrm{~nm}) / \mathrm{mCP}(10 \mathrm{~nm}) / 10 \mathrm{wt} \%$ emitter:DPEPO $(25 \mathrm{~nm}) / \mathrm{TSPO} 1(5 \mathrm{~nm}) / \mathrm{TPBi}(40 \mathrm{~nm}) / \mathrm{LiF}(1.5 \mathrm{~nm}) / \mathrm{Al}(200 \mathrm{~nm})^{l} \mathrm{ITO} / \mathrm{MoO}_{3}(10$ $\mathrm{nm}) / \mathrm{TAPC} / \mathrm{TCTA} / 10 \mathrm{wt} \%$ emitter-doped CBP $/ \mathrm{TmPyPB} / \mathrm{LiF}(1 \mathrm{~nm}) / \mathrm{Al}^{m}{ }^{m}$ no data provided. 


\section{Phenoxazine and phenothiazine substituent}

The phenoxazine and phenothiazine fragments are also considered as classical ED groups for push-pull TADF chromophore structures. They are considered as stronger ED moieties than acridan derivatives. ${ }^{2}$ Stronger ICT is therefore observed in push-pull structure inducing a redshifted emission to green-yellow region of the spectrum. ${ }^{45,66,83,84}$ Phenoxazine and phenothiazine fragments can be grafted on the pyrimidine core via phenylene linker either by Buchwald-Hartwig cross-coupling reaction on bromophenylpyridine derivatives ${ }^{85,86}$ or by Suzuki cross-coupling reaction of boronic acids/esters of $N$-phenylphenoxazine. ${ }^{86}$

Compounds 39a and 39b (Chart 16) were studied theoretically and compared to their 1,3,5triazine analogue. ${ }^{87}$ Using TD-DFT and the semi-classical Marcus Theory approach, the TADF capacities were estimated through the SOC, $\Delta \mathrm{E}_{\mathrm{ST}}$ and $\mathrm{k}_{\mathrm{RISC}}$ values. It was found that 39a exhibit a $\mathrm{k}_{\text {RISC }}$ value of $1.67 .10^{3} \mathrm{~s}^{-1}$ and 39b of $9.86 .10^{4} \mathrm{~s}^{-1}$. This difference is attributed to the presence of intramolecular hydrogen bonds in $39 \mathrm{~b}$, improving the rigidity of the structure and minimizing the $\Delta \mathrm{E}_{\mathrm{ST}}$. 39b is thus suggested to be further explored for TADF blue emitters.

Compound 40 (Chart 16) is the analogue of dimethylacridan derivative 27 (Chart 11). ${ }^{72}$ This compound exhibits red-shifted delayed fluorescence and higher PLQY than 27 (Table 5). In terms of OLED performances, electroluminescence of $\mathbf{4 0}$, centered at $524 \mathrm{~nm}$, is red-shifted by $37 \mathrm{~nm}(0.18 \mathrm{eV})$ with respect to 27 . As generally observed in case of a bathochromic shift of electroluminescence to yellow/green region, this is accompanied by an increase in the external quantum efficiency and power efficiency (Table 6).

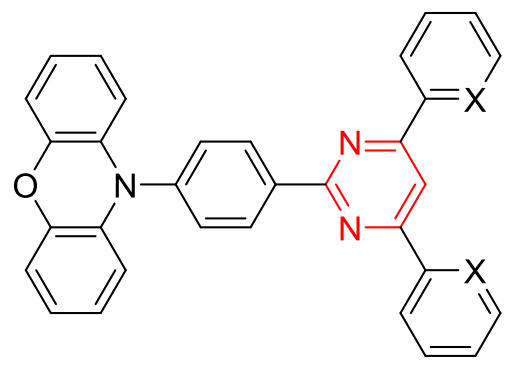

$39 \mathrm{a} X=\mathrm{CH}$ $39 b \times=N$

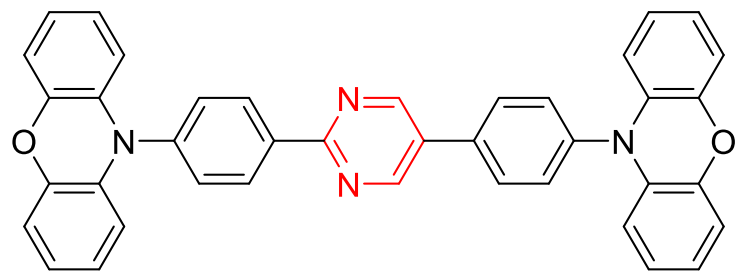

40

Chart 16. Structure of 2-substituted and 2,5-disubstituted pyrimidine derivatives $\mathbf{3 9}$ and $\mathbf{4 0}$ with phenothiazine fragments.

4,6-bis(4-(10H-phenoxazin-10-yl)phenyl)pyrimidine derivatives 41 were designed by various teams (Chart 17). ${ }^{85,88,89}$ The X-ray structure of compound $\mathbf{4 1 \mathbf { b }}$ reveals a pre-twisted molecular structure with torsion angles between the phenoxazine fragments and the phenylene linkers of 87.4 and $68.0^{\circ}$. With respect to their dimethylacridan analogues 26a-c, the compounds 41 a-c exhibit red-shifted maximum emission wavelengths in toluene. Depending on the structure of the OLED, green electroluminescence is observed with $\mathrm{EQE}_{\max }$ up to $29.5 \%$ for emitter $41 \mathrm{a}$ (Table 6). The presence of a substituent $\mathrm{R}^{1}$ at the $\mathrm{C} 2$ position of the pyrimidine ring (Figure 2) does not significantly modify the photophysical properties (Table 5): adding a phenyl ring or a 4(pyridin-2-yl)phenyl unit only slightly increases the EQE of the OLED. The presence of methyl groups on the phenylene linkers (compounds 41f-41g) induces a blue-shifted emission and a reduction of the delayed fluorescence lifetime of $\mathbf{4 1 g}$ (with methyl groups at the ortho position of the phenoxazine groups in the phenylene linker), associated with a slight increase of $\mathrm{EQE}_{\max }$ and a reduction of the EQE roll-off. 
<smiles>[R]c1cc(-c2cc([R])c([R])nc2[R])c([R])cc1-c1cc([R])c(N2c3ccccc3Oc3ccccc32)cc1[R]</smiles>

41a: $R^{1}=R^{2}=R^{3}=H$

41b: $R^{1}=M e, R^{2}=R^{3}=H$

41c: $R^{1}=P h, R^{2}=R^{3}=H$

41d: $R^{1}=4$-(pyridin-2-yl)phenyl, $R^{2}=R^{3}=H$

41e: $R^{1}=4$-(4,6-diphenyl-1,3,5-triazin-2-yl), , $R^{2}=R^{3}=H$

41f: $R^{1}=R^{3}=H, R^{2}=M e$

41g: $R^{1}=R^{2}=H, R^{3}=M e$

41h: $R^{1}=H, R^{2}=R^{3}=M e$

Chart 16. Structure of 4,6-disubstituted pyrimidine derivatives 41 with phenothiazine fragments.

Phenothiazine-substituted pyrimidine are rather rare in the literature. In addition to compound 10c, 4,6-bis(4-(10H-phenothiazin-10-yl)phenyl)pyrimidines $\mathbf{4 2}$ were designed by Serevičius

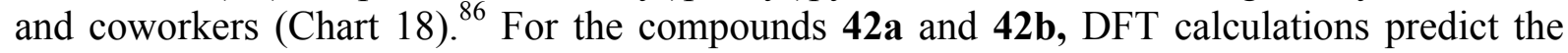
coexistence of QE and QA conformers, whereas for 42c only the QE conformer is expected, taking into account that the rotation of the phenothiazine units was impeded by additional methyl groups. These predictions were confirmed by fluorescence measurements in toluene after excitation at 300-350 $\mathrm{nm}$ where three distinct emission bands were observed for 42a and 42b: low intensity ${ }^{1} \mathrm{LE}$, and ${ }^{1} \mathrm{CT}_{\mathrm{QA}}\left({ }^{1} \mathrm{CT}\right.$ fluorescence from QA conformer) together with very intense ${ }^{1} \mathrm{CT}_{\mathrm{QE}}$ fluorescence $\left({ }^{1} \mathrm{CT}\right.$ fluorescence of $\mathrm{QE}$ conformations) at 544-574 $\mathrm{nm}$. In contrast, only ${ }^{1} \mathrm{LE}$ and ${ }^{1} \mathrm{CT}_{\mathrm{QE}}$ fluorescence bands were observed for $42 \mathrm{c}$. The presence of a chlorine atom in the structure of $\mathbf{4 2 b}$ enhances TADF due to the heavy atom effect that increases the process related to SOC. This compound exhibits a significantly lower delayed fluorescence lifetime and a significantly higher delayed/prompt fluorescence ratio than $\mathbf{4 2 a}$ and 42c (1.2 vs. 0.3 and 0.03 for 42a and 42c, respectively).

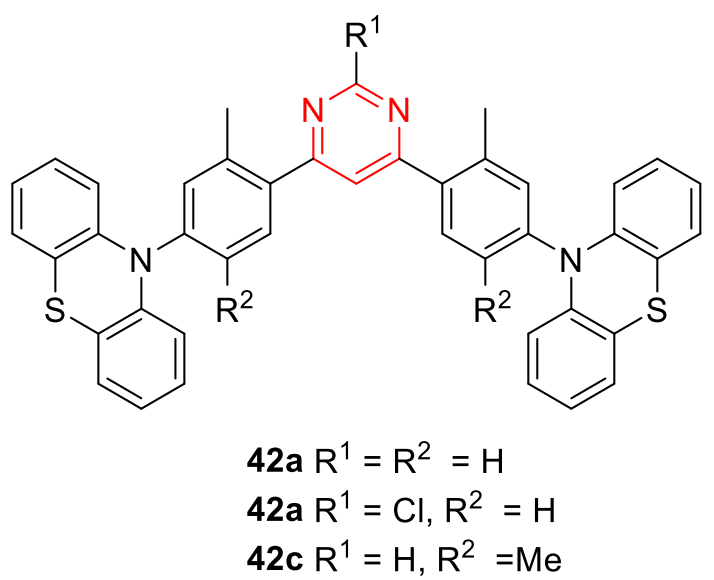

Chart 18. Structure of 4,6-disubstituted pyrimidine derivatives $\mathbf{4 2}$ with phenothiazine fragments. 
Table 5: Photophysical data of phenoxazine and phenothiazine substituted pyrimidine TADF chromophores

\begin{tabular}{|c|c|c|c|c|c|}
\hline Compds & $\Delta \mathrm{E}_{\mathrm{ST}}(\mathrm{eV})$ & $\lambda_{\mathrm{em}}(\mathrm{nm})$ & PLQY & $\tau_{\mathrm{PF}}(\mathrm{ns}) / \tau_{\mathrm{DF}}(\mu \mathrm{s})$ & Reference \\
\hline $10 \mathbf{b}^{a}$ & 0.082 & 549 & $0.27(0.85)$ & $24 / 1.0$ & 59 \\
\hline $10 c^{a}$ & 0.111 & 557 & $0.19(0.72)$ & $13 / 0.65,3.4$ & 59 \\
\hline $40^{b}$ & $-e$ & 537 & 0.78 & $17 / 287$ & 72 \\
\hline $41 a^{c}$ & 0.08 & 535 & 0.88 & $-{ }^{e} / 2.56$ & 88 \\
\hline $41 a^{d}$ & 0.04 & 521 & 1.00 & $20.2 / 2.56$ & 89 \\
\hline $41 a^{a}$ & $-e$ & 543 & 0.42 & $13.3 / 1.6$ & 85 \\
\hline $41 b^{c}$ & 0.10 & 524 & 0.89 & $--^{e} / 2.11$ & 88 \\
\hline $41 c^{c}$ & 0.03 & 528 & 0.91 & $-{ }^{e} / 1.95$ & 88 \\
\hline $41 d^{d}$ & 0.07 & 524 & 1.00 & $19.4 / 2.77$ & 89 \\
\hline $41 \mathrm{e}^{d}$ & 0.05 & 528 & 0.93 & $20.4 / 2.79$ & 89 \\
\hline $41 f^{a}$ & $-e$ & 528 & 0.38 & $25.0 / 4.0$ & 85 \\
\hline $41 \mathrm{~g}^{a}$ & $-e$ & 530 & 0.52 & $16.4 / 0.8$ & 85 \\
\hline $41 h^{a}$ & $-e$ & 519 & 0.53 & $23.8 / 2.1$ & 85 \\
\hline $42 a^{a}$ & 0.187 & 535 & 0.04 & $10 / 11$ & 87,90 \\
\hline $42 b^{a}$ & 0.156 & 575 & $-^{e}$ & $-e^{e} / 1.1$ & 86 \\
\hline $42 c^{a}$ & 0.025 & 544 & $-{ }^{e}$ & $-{ }^{e} / 6$ & 86 \\
\hline
\end{tabular}

${ }^{a}$ in deoxygenated toluene solution ${ }^{b}$ in $6 \mathrm{wt} \%$ PTT film ${ }^{c}$ in $6 \mathrm{wt} \% \mathrm{CBP}$ film ${ }^{d}$ in 9-(3-(9Hcarbazol-9-yl)phenyl)-9H-carbazole-3-carbonitrile ( $\mathrm{mCPCN})$ film $6 \mathrm{wt} \%{ }^{e}$ no data provided

Table 6: OLED characteristics of phenoxazine substituted pyrimidine TADF chromophores

\begin{tabular}{|l|l|l|l|l|l|}
\hline Compds & $\begin{array}{l}\text { EQE } \\
(\mathbf{\%})\end{array}$ & $\begin{array}{l}\mathbf{E Q E}_{\mathbf{1 0 0}} \\
(\%)\end{array}$ & $\begin{array}{l}\mathbf{L u m}_{\max } \\
\left(\mathbf{l m W}^{-1}\right)\end{array}$ & $\mathbf{C I E} / \boldsymbol{\lambda}_{\mathbf{E L}} \mathbf{( n m )}$ & Reference \\
\hline $\mathbf{4 0}^{a}$ & 16.8 & $-{ }^{e}$ & 41 & $(0.29 ; 0.51) / 524$ & 72 \\
\hline $\mathbf{4 1 a}^{b}$ & 19.9 & 17.8 & 60.1 & $(0.33 ; 0.57) /-^{e}$ & 88 \\
\hline $\mathbf{4 1 a}^{c}$ & 29.5 & $-^{e}$ & 103.5 & $(0.33 ; 0.58) / 528$ & 85 \\
\hline $\mathbf{4 1 a}^{d}$ & 27.9 & 18.0 & 84.1 & $(0.35 ; 0.56) / 536$ & 89 \\
\hline $\mathbf{4 1 b}^{b}$ & 22.2 & 19.8 & 71.3 & $(0.30 ; 0.56) /-^{e}$ & 88 \\
\hline $\mathbf{4 1 c}^{b}$ & 24.6 & 21.9 & 80.0 & $(0.32 ; 0.57) /-^{e}$ & 88 \\
\hline $\mathbf{4 1 d}^{c}$ & 33.9 & $-^{e}$ & 118.9 & $(0.33 ; 0.58) / 528$ & 89 \\
\hline $\mathbf{4 1 e}^{c}$ & 30.1 & $-{ }^{e}$ & 106.1 & $(0.33 ; 0.58) / 528$ & 89 \\
\hline $\mathbf{4 1 f}^{d}$ & 27.5 & 21.0 & 75.2 & $(0.27 ; 0.49) / 514$ & 85 \\
\hline $\mathbf{4 1 g}^{d}$ & 29.1 & 25.0 & 74.1 & $(0.32 ; 0.55) / 529$ & 85 \\
\hline $\mathbf{4 1 h}^{d}$ & 26.3 & 16.9 & 53.3 & $(0.23 ; 0.42) / 502$ & 85 \\
\hline
\end{tabular}

${ }^{a}$ ITO/ HATCN $(10 \mathrm{~nm}) / \alpha$-NPD $(30 \mathrm{~nm}) / \mathrm{mCP}(5 \mathrm{~nm}) / 6 \mathrm{wt} \%$ emitter-doped PPT $(30 \mathrm{~nm}) /$ TPBi $(40 \mathrm{~nm}) / \mathrm{LiF}(0.8 \mathrm{~nm}) / \mathrm{Al}(80 \mathrm{~nm}){ }^{b}$ ITO/TAPC $(30 \mathrm{~nm}) /$ TcTa $(5 \mathrm{~nm}) / C B P:$ TADF emitters $(6$ wt $\%, 15 \mathrm{~nm}) / \operatorname{Tm} 3$ PyPB $(65 \mathrm{~nm}) / \mathrm{LiF}(1 \mathrm{~nm}) / \mathrm{Al}(100 \mathrm{~nm}){ }^{c} \mathrm{ITO} / \mathrm{MoO}_{3}(1$ $\mathrm{nm}) / 1,1$-bis[(di-4-tolylamino)phenyl]-cyclohexane $(60 \mathrm{~nm}) / N, N$-dicarbazolyl-3,5-benzene $(10$ $\mathrm{nm}) / \mathrm{mCPCN}$ : TADF emitters $(6 \mathrm{wt} \%, 20 \mathrm{~nm}) /$ tris-[3-(3-pyridyl)mesityl]borane $(55 \mathrm{~nm}) / \mathrm{LiF}$ $(1 \mathrm{~nm}) / \mathrm{Al}{ }^{d}$ ITO/TAPC $(30 \mathrm{~nm}) / \mathrm{TcTa}(5 \mathrm{~nm}) / 10 \mathrm{wt} \%$ TADF emitter:DPEPO $(15 \mathrm{~nm}) /$ TmPyPB $(65 \mathrm{~nm}) / \mathrm{LiF}(0.8 \mathrm{~nm}) / \mathrm{Al}(100 \mathrm{~nm})^{e}$ no data provided

Very recently, some Ir(III) and Pt(II) metal complexes of pyrimidine-based ligands exhibiting TADF properties were also described (Chart 19). ${ }^{91,92,93,94}$ Within these complexes, the TADF nature of the emission was demonstrated by a strong decrease of photoluminescence intensity below $230 \mathrm{~K}$. It appears that, unlike mononuclear analogues, bimetallic structures tend to promote favorable conditions for the occurrence of TADF due to smaller $\Delta \mathrm{E}_{\mathrm{ST}}$ and larger 
singlet oscillator strength. The replacement of chlorine by iodine as ancillary ligand in complex Pt3 results in a more pronounced reduction of $\Delta \mathrm{E}_{\mathrm{ST}}$. The role of iodine is related to the destabilization of the HOMO orbital. These complexes were used in red and near-infrared OLEDwith promising performances.

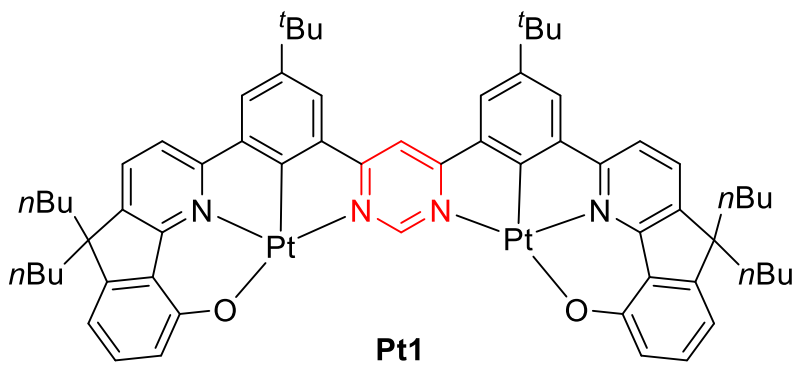

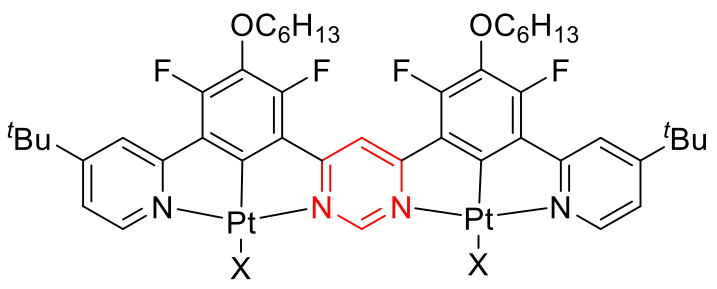

Pt2 $\mathrm{X}=\mathrm{Cl}$

Pt3 $X=1$

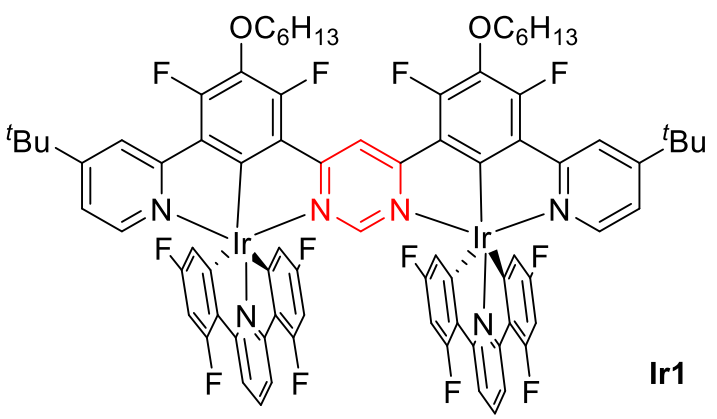

Chart 17. Structure of pyrimidine based di-Pt(II) and di-Ir(III) complexes

\section{Pyrazine chromophores}

Pyrazine TADF chromophores are much scarcer than pyrimidine derivatives and appeared only in the last two years in the literature. To the best of our knowledge, they have been combined with either carbazole or triphenylamine ED.

Carbazole fragments can be grafted on the pyrazine core by Ullmann Cu-catalyzed crosscoupling reaction starting from chloropyrazine derivatives ${ }^{95}$ or by nucleophilic aromatic substitution (SNAr). ${ }^{96}$ Phenylcarbazole fragment can be connected to a pyrazine core by Suzuki cross-coupling reaction from chloropyrazine derivatives and the corresponding boronic acid of carbazole. ${ }^{97}$

Adachi and Zysman-Colman have designed the chromophores 43. ${ }^{95}$ These linear compounds combine a pyrazine/bipyrazine weak EA central core with two di-tert-butyl carbazole groups as weak ED at the periphery. When compared to compound 1, which has a 4,6-disubstituted pyrimidine core, a lower $\Delta \mathrm{E}_{\mathrm{ST}}$ value is observed in polymeric matrix (Table 7). The decay lifetimes show temperature dependence in a PPT host, in agreement with TADF emission. Both molecules show blue emission with PLQY close to $60 \%$. Deep-blue and sky-blue OLEDwere fabricated with emitters $\mathbf{4 3 a}$ and $\mathbf{4 3 b}$, respectively. These devices, with $\mathrm{EQE}_{\max }$ of 11,6 and $7.2 \%$ exhibit significant efficiency roll-off at high luminance.

Ai and Zhang proposed the o-phenylene bridged carbazole substituted cyanopyrazines 44 (Chart 17). ${ }^{97}$ Both compounds show particularly small $\Delta \mathrm{E}_{\mathrm{ST}}$ (below $0.1 \mathrm{eV}$, Table 7 ) and exhibit TADF blue emission. The delayed emission is significantly faster for 44a than for 44b. The emitters 44a and 44b were used for sky-blue emitting OLEDs, with a significant

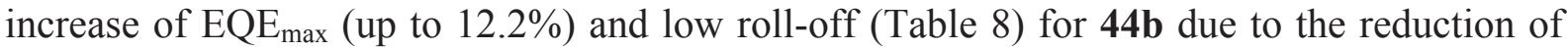
the non-radiative decay of its $\mathrm{T}_{1}$. 
Makhseed et al have reported a series of multicarbazole substituted (cyano)pyrazine derivatives 45 (Chart 17). ${ }^{96}$ These compounds exhibit TADF emission in doped PEDOT thin filmss and are characterized by color stability due to their resistance to intermolecular dimerization. In this series, when increasing the number of carbazole both the $\Delta \mathrm{E}_{\mathrm{ST}}$ and the delayed fluorescence lifetime increase and the emission is sizeably red shifted (Table 7).

Compound 46 (Chart 17), in which the pyrazine ring plays the role of $\pi$-linker, shows redshifted emission with similar $\triangle \mathrm{E}_{\mathrm{ST}}$ and PLQY values as compared to its pyrimidine analogue 21 (Tables 1 and 7). ${ }^{62}$ With the pyrazine bridge, a larger $\mathrm{EQE}_{\max }$ and reduced efficiency rolloff are observed when compared to the pyrimidine bridge. However, due to the stronger acceptor strength of the sulfonylbispyrazine fragment, a green OLED is obtained instead of a blue one (Table 8).

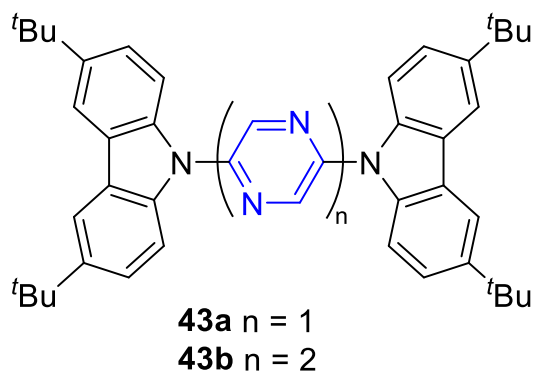<smiles>[R]c1ccc(-n2c3ccc(C(C)(C)C)cc3c3cc(C(C)(C)C)ccc32)c(-c2nccnc2C#N)c1</smiles>

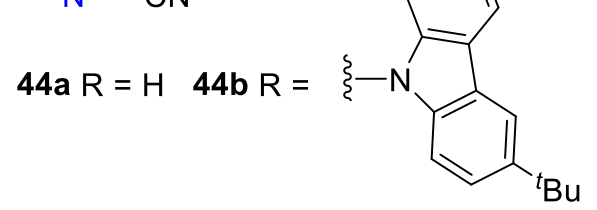<smiles>[R]c1nc(-n2c3ccccc3c3ccccc32)nc(-n2c3ccccc3c3ccccc32)c1[R]</smiles>

45a $\mathrm{R}^{1}=\mathrm{R}^{2}=\mathrm{CN}$

45b $R^{1}=$ carbazol-9-yl, $R^{2}=C N$ 45c $\mathrm{R}^{1}=\mathrm{R}^{2}=$ carbazol-9-yl<smiles>CC(C)(C)c1ccc2c(c1)c1cc(C(C)(C)C)ccc1n2-c1cnc(S(=O)(=O)c2cnc(-n3c4ccc(C(C)(C)C)cc4c4cc(C(C)(C)C)ccc43)cn2)cn1</smiles>

Chart 17. Structure of carbazole substituted pyrazine derivatives 43-46

Liang and coworkers have designed the chromophore 47 with two dicyanopyrazine fragment grafted on a triphenylamine central core (Chart 18). ${ }^{98}$ DFT calculations indicate that the dihedral angles between the triphenylamine and the pyrazine fragment amount to about $60^{\circ}$. Despite the rather high $\Delta \mathrm{E}_{\mathrm{ST}}$ value experimentally observed (Table 7), this compound exhibits orange TADF emission in doped films. Meanwhile, rather modest OLED performances are observed with this emitter (Table 8).

Kido and Sasabe have designed the V-shaped disubstituted pyrazine derivatives 48 (Chart 19). ${ }^{99}$ When compared with their 4,6-disubstituted pyrimidine analogues 26a and 41a, the chromophores 48 display higher $\Delta \mathrm{E}_{\mathrm{ST}}$ and blue-shifted emission spectra (Tables 3, 5 and 7). Light-blue and green OLEDwere achieved with emitters $\mathbf{4 8 a}$ and $\mathbf{4 8 b}$, respectively, with significantly lower $\mathrm{EQE}_{\max }$ than their pyrimidine analogues (Tables 4, 6 and 8). Noteworthy, compound 48a was shown to form an in-situ complex with $\mathrm{Cu}(\mathrm{I})$ through a co-evaporation process, leading to an efficient white emitting OLED. 
<smiles>N#Cc1nc(-c2ccccc2)c(-c2ccc(N(c3ccccc3)c3ccc(-c4nc(C#N)c(C#N)nc4-c4ccccc4)cc3)cc2)nc1C#N</smiles>

47

Chart 18. Structure of triphenylamine substituted pyrazine derivative 47 .<smiles>[X]c1ccccc1N(c1ccccc1)c1ccc(-c2cncc(-c3ccc(N(c4ccccc4[X])c4ccccc4[X])cc3)n2)cc1</smiles>

Chart 19. Structure of dimethylacridan and phenoxazine substituted pyrazine derivatives 48

Table 7: Photophysical data of pyrazine and pyridazine TADF chromophores

\begin{tabular}{|l|l|l|l|l|l|}
\hline Compds & $\Delta \mathbf{E}_{\mathbf{S T}}(\mathbf{e V})$ & $\lambda_{\text {em }}(\mathbf{n m})$ & $\mathbf{P L Q Y}$ & $\tau_{\mathbf{P F}}(\mathbf{n s}) / \tau_{\mathbf{D F}}(\boldsymbol{\mu s})$ & Reference \\
\hline $\mathbf{4 3 a}^{a}$ & 0.27 & 455 & $0.58(0.70)$ & $\begin{array}{l}7.2(77.7 \%), 10.7 \\
(22.3 \%) / 4.2\end{array}$ & 95 \\
\hline $\mathbf{4 3 b}^{a}$ & 0.38 & 485 & $0.60(0.65)$ & $\begin{array}{l}1.3 \quad(16.9 \%) \quad 3.4 \\
(71.7 \%) 7.6(11.3 \%) \\
/ 4.0\end{array}$ & 95 \\
\hline $\mathbf{4 4 a}^{b, e}$ & 0.07 & 483 & 0.47 & $9.7 / 1.9$ & 97 \\
\hline $\mathbf{4 4 b}^{b, e}$ & 0.06 & 493 & 0.44 & $7.2 / 8.1$ & 97 \\
\hline $\mathbf{4 5 a}^{c}$ & 0.15 & 495 & 0.11 & $4.3 / 4.0$ & 96 \\
\hline $\mathbf{4 5 b}^{c}$ & 0.29 & 540 & 0.24 & $6.9 / 99.2$ & 96 \\
\hline $\mathbf{4 5 c}^{c}$ & 0.34 & 560 & 0.36 & $5.0 / 174$ & 96 \\
\hline $\mathbf{4 6}^{c}$ & 0.16 & 510 & 0.68 & $10 / 108$ & 62 \\
\hline $\mathbf{4 7}^{d, e}$ & 0.39 & 581 & 0.28 & $6.6 / 249$ & 98 \\
\hline $\mathbf{4 8 a}^{c}$ & 0.36 & 475 & 0.48 & $-{ }^{f} / 134$ & 99 \\
\hline $\mathbf{4 8 b}^{d}$ & 0.21 & 519 & 0.65 & $-{ }^{f} / 54$ & 99 \\
\hline $\mathbf{4 9 b}^{c}$ & 0.25 & 470 & 0.022 & $10.7(86.9 \%), 61.2$ & 100 \\
& & & & $(12.6 \%) / 1.69$ & \\
\hline $\mathbf{4 9 c}^{c}$ & 0.15 & 520 & 0.13 & $40.9 / 1.43$ & 100 \\
\hline
\end{tabular}

${ }^{a}$ in $7 \mathrm{wt} \% \mathrm{wt}$ PPT thin films ${ }^{b}$ in $10 \mathrm{wt} \% \mathrm{mCP}$ thin films ${ }^{c}$ in $10 \mathrm{wt} \%$ DPEPO thin films ${ }^{d}$ in $10 \% \mathrm{CBP}$ thin films ${ }^{e} \Delta \mathrm{E}_{\mathrm{ST}}$ in toluene ${ }^{f}$ no data provided 
Table 8: OLED characteristics of pyrazine and pyridazine TADF chromophores

\begin{tabular}{|l|l|l|l|l|l|}
\hline Compds & $\begin{array}{l}\text { EQE } \\
\mathbf{( \% )}\end{array}$ & $\begin{array}{l}\text { EQE } \\
\mathbf{( \% )}\end{array}$ & $\begin{array}{l}\mathbf{L u m}_{\max } \\
\mathbf{( l m W}^{-1} \mathbf{)}\end{array}$ & CIE / $\boldsymbol{\lambda}_{\mathbf{E L}} \mathbf{( n m )}$ & Reference \\
\hline $\mathbf{4 3 a}^{a}$ & 11.6 & 4.5 & 11 & $(0.15 ; 0.16) / 460$ & 95 \\
\hline $\mathbf{4 3 b}^{a}$ & 7.2 & 3.8 & 11 & $(0.15 ; 0.30) / 484$ & 95 \\
\hline $\mathbf{4 4 a}^{b}$ & 7.6 & $-{ }^{h}$ & $-{ }^{h}$ & $(0.15 ; 0.29) / 483$ & 97 \\
\hline $\mathbf{4 4 b}^{b}$ & 12.2 & $-{ }^{h}$ & $-{ }^{h}$ & $(0.15 ; 0.26) / 480$ & 97 \\
\hline $\mathbf{4 6}^{c}$ & 18.0 & 14.0 & $-{ }^{h}$ & $(0.31 ; 0.53) / 522$ & 62 \\
\hline $\mathbf{4 7}^{d}$ & 4.4 & 1.8 & 6.6 & $-{ }^{h} / 576$ & 98 \\
\hline $\mathbf{4 8 a}^{e}$ & 11.9 & 4.8 & 25.1 & $(0.19 ; 0.31) /-^{h}$ & 99 \\
\hline $\mathbf{4 8 b}^{f}$ & 21.4 & 17.3 & 76.0 & $(0.31 ; 0.55) /-^{h}$ & 99 \\
\hline $\mathbf{4 9 c}^{g}$ & 5.8 & 5.6 & 10.8 & $(0.30 ; 0.6) / 520$ & 100 \\
\hline
\end{tabular}

${ }^{a}$ ITO/TAPC $(40 \mathrm{~nm}) / \mathrm{mCP}(10 \mathrm{~nm})$ TPP:emitter $(7 \mathrm{wt} \%)(30 \mathrm{~nm}) / \mathrm{PPT}(10 \mathrm{~nm})$ TmPyPB (30 $\mathrm{nm}) / \mathrm{LiF}(0.7 \mathrm{~nm}) / \mathrm{Al}(100 \mathrm{~nm}){ }^{b} \mathrm{ITO} / \mathrm{MoO}_{3} / \mathrm{mCP}(40 \mathrm{~nm}) / \mathrm{mCP}$ :emitter $(30 \mathrm{wt} \%$ for 44a 10 wt $\%$ for $44 \mathbf{b}) / \mathrm{PPT}(40 \mathrm{~nm}) / \mathrm{Liq} / \mathrm{Al}{ }^{c}$ ITO/ TAPC $(40 \mathrm{~nm}) / \mathrm{mCP} \quad(10 \mathrm{~nm}) / 10$ wt $\%$ emitter:DPEPO (30 nm)/DPEPO $(10 \mathrm{~nm}) / \mathrm{TmPyPB}(40 \mathrm{~nm}) / \mathrm{LiF}(1 \mathrm{~nm}) / \mathrm{Al}(100 \mathrm{~nm}){ }^{d} \mathrm{ITO} /$ TAPC (50 nm)/TCTA $(5 \mathrm{~nm}) / \mathrm{CBP}: 10 \mathrm{wt} \%$ emitters $(20 \mathrm{~nm}) / \mathrm{TmPyPb}(45 \mathrm{~nm}) / \mathrm{LiF}(1 \mathrm{~nm}) / \mathrm{Al}$ $(100 \mathrm{~nm}){ }^{e}$ ITO/PPBI $(20 \mathrm{~nm}) /$ TAPC $(20 \mathrm{~nm}) / \mathrm{mCP}:$ emitter $(10 \mathrm{wt} \%)(10 \mathrm{~nm}) /$ DPEPO:emitter $(10 \mathrm{wt} \%)(10 \mathrm{~nm}) / \mathrm{B} 3 \mathrm{PyPB}(50 \mathrm{~nm}) / \mathrm{LiF}(0.5 \mathrm{~nm}) / \mathrm{Al}(100 \mathrm{~nm})^{f}$ ITO/PPBI $(20 \mathrm{~nm}) / \mathrm{TAPC}(20$ $\mathrm{nm}) /$ TCTA:emitter $(10 \mathrm{wt} \%)(10 \mathrm{~nm}) / \mathrm{CBP}:$ emitter $(10 \mathrm{wt} \%)(10 \mathrm{~nm}) / \mathrm{B} 3 \mathrm{PyPB}(50 \mathrm{~nm}) / \mathrm{LiF}$ $(0.5 \mathrm{~nm}) / \mathrm{Al}(100 \mathrm{~nm}),{ }^{g}$ ITO $(90 \mathrm{~nm}) /$ TAPC $(35 \mathrm{~nm}) / \mathrm{mCP}(10 \mathrm{~nm}) / 49 \mathrm{c}: D P E P O(15 \mathrm{wt} \%$, $30 \mathrm{~nm}) / \mathrm{TPBi}(45 \mathrm{~nm}) / \operatorname{LiF}(1 \mathrm{~nm}) / \mathrm{Al}(100 \mathrm{~nm}) .{ }^{h}$ no data provided

\section{Pyridazine chromophores}

To the best of our knowledge, only three pyridazine structures have been reported so far. They have been designed by Zysman-Colman, Samuel and coworkers in the prospect to develop TADF emitters (compounds 49, Chart 20). ${ }^{100}$ The carbazole and dimethylacridan derivatives 49a and 49b do not exhibit significant TADF emission in a DPEPO host material. This is not surprising as compound 49a is not emissive at all and only a weak delayed fluorescence signal is observed for 49b. Compound 49c with the stronger phenoxazine ED shows appreciable delayed emission with moderate PLQY (Table 7) and is sensitive to the presence of $\mathrm{O}_{2}$, which decreases with the temperature down to $77 \mathrm{~K}$. A green OLED was achieved using 49c as emitter in the device that exhibits a moderate $\mathrm{EQE}_{\max }$ of $5.4 \%$ (Table 8 ).<smiles>Cc1ccc(-c2cc(-n3c4ccccc4c4ccccc43)cc(-n3c4ccccc4c4ccccc43)c2)nn1</smiles><smiles></smiles>
$49 \mathrm{~b} X=\mathrm{CMe}_{2}$ $49 c X=0$

Chart 20. Structure of pyridazine TADF chromophores 49 


\section{Conclusion and outlooks}

In summary, the pyrimidine core appears as a wonderful and promising platform for the elaboration of TADF chromophores for the optimization of OLEDs, displaying small $\Delta \mathrm{E}_{\mathrm{ST}}$ and short delayed fluorescence lifetimes, in the $\mu$ s range. Carbazole derivatives of pyrimidine appear particularly appealing for deep-blue OLEDwith $\mathrm{EQE}_{\max }$ values among the best reported to date. In terms of position of substitution, $\mathrm{C} 4$ substituted pyrimidine derivatives exhibit generally better TADF ( $\Delta \mathbf{E}_{\mathbf{S T}}$, PLQY) properties and OLED performances than their $\mathrm{C} 2$ substituted analogues. V-shaped $\mathrm{C} 4$ and $\mathrm{C} 6$ disubstituted pyrimidines exhibit red-shifted emission and appears to be the most closely studied scaffold to design pyrimidine-based TADF emitters. Acridan fragments are particularly developed for blue and sky-blue emission and design engineering, with the inclusion of the spiroacridan group has proved beneficial for improved TADF properties and OLED performances. For instance, incorporation of a Vshaped pyrimidine emitter with two phenyl fluorene-spiroacridan fragments in position $\mathrm{C} 4$ and $\mathrm{C6}$ in an OLED led to sky-blue emission with a record $\mathrm{EQE}_{\max }$ value of $30.5 \%$. Pyrimidine chromophores bearing stronger ED phenoxazine fragments are useful for the conception of green OLEDs. To the best of our knowledge, so far, no pyrimidine-based purely organic chromophore has led to any red or near infrared emitting OLED. A recent work reported bimetallic platinum(II) complexes with a pyrimidine ligand that presents TADF properties promising for red/near infrared OLED not reachable with purely organic emitters.

The development of other diazine-based TADF emitters is still in its infancy and leaves much room for artificially tailored molecular engineering. With pyrazine derivatives, TADF performances seem slightly lower than their pyrimidine analogues. Still, the lower electrondeficiency of pyrazine with regards to pyrimidine may be interesting to develop blue-shifted emission. Some Blue TADF chromophores are now ready for commercial production. ${ }^{101}$ Pyrimidine derivatives could reveal particularly interesting in this prospect but a couple of challenges remain to be tackled. Among those, long-term stability and efficiency roll-off at high brightness are noteworthy. Further increasing the EQE up to 40 or even $50 \%$ would be a major breakthrough.

Design of novel and efficient diazine-based TADF chromophores shall further benefit from highly desirable in-depth analysis of structure-properties relationships. In fact, to date it remains relatively limited compared to that already implemented for other classes of TADF chromophores. From a theoretical perspective, the diazine derivatives are mostly treated with vertical and semi-classic approaches, whereas more involved levels of theory such as (spin)vibronic models ${ }^{10}$ have yet to be applied in order to possibly reach a quantitative description and prediction of their TADF abilities. From an experimental perspective, time-resolved spectroscopy combined to synthetic strategies such as steric confinement ${ }^{73}$ or insertion of electronically/optically innocent bulky groups ${ }^{76}$ shall also provide valuable information to understand the complex vibrational coupling mechanisms mediating ISC/RISC that in turn influence the emission properties. Last but not least, thermally activated up-conversion of the triplet exciton may also find applications in other fields such as photocatalysis ${ }^{102}$ and biomedical applications, ${ }^{103} \mathrm{X}$-ray scintillation and radiation detection. ${ }^{104}$

\footnotetext{
${ }^{1}$ Y. Tao, K. Yuan, T. Chen, P. Xu, H. Li, R. Chen, C. Zheng, L. Zhang and W. Huang, $A d v$. Mater., 2014, 26, 7931-7958.

${ }^{2}$ M. Y. Wong and E. Zysman-Colman, Adv. Mater., 2017, 29, 1605444.

${ }^{3}$ J. Lee, K. Shizu, H. Tanaka, H. Nomura, T. Yasuda and C. Adachi, J. Mater. Chem. C, 2013, 1, 4599-4604.
} 
${ }^{4}$ F. B. Dias, K. N. Bourdakos, V. Jankus, K. C. Moss, K. T. Kamtekar, V. Bhalla, J. Santos, M. R. Bryce and A. P. Monkman, Adv. Mater., 2013, 25, 3707-3714.

${ }^{5}$ R. Dhali, D. K. A. Phan Huu, F. Bertocchi, C. Sissa, F. Terenziani and A. Painelli, Phys. Chem. Chem. Phys. 2021, 3, 378-387.

${ }^{6}$ M. A. El-Sayed, J. Chem. Phys., 1963, 38, 2834-2838

${ }^{7}$ M. K. Etherington, F. Franchello, J. Gibson, T. Northey, J. Santos, J. S. Ward, H. F. Higginbotham, P. Data, A. Kurowska, P. L. Dos Santos, D. R. Graves, A. S. Batsanov, F. B. Dias, M. R. Bryce, T. J. Penfold and A. P. Monkman, Nat. Commun., 2017, 8, 14987.

${ }^{8}$ F. B. Dias, J. Santos, D. R. Graves, P. Data, R. S. Nobuyasu, M. A. Fox, A. S. Batsanov, T. Palmeira, M. N. Berberan-Santos, M. R. Bryce and A. P. Monkman, Adv. Sci., 2016, 3, 1600080 .

${ }^{9}$ a) P. L. dos Santos, M. K. Etherington and A. P. Monkman, J. Mater. Chem. C, 2018, 6, 4842-4853.

10 a) J. Gibson, A. P. Monkman and T. J. Penfold, ChemPhysChem, 2016, 17, 2956-2961; b) I. Kim, S. O. Jeon,; D. Jeong, H. Choi, W.-J. Son, D. Kim, Y M. Rhee and H. S. Lee, J. Chem. Theory Comput., 2020, 16, 621-632.

${ }^{11}$ C. A. Parker and C. G. Hatchard, Trans. Faraday Soc., 1961, 57, 1894-1904.

12 A. Endo, K. Sato, K. Yoshimura, T. Kai, A. Kawada, H. Miyazaki and C. Adachi, Appl. Phys. Lett., 2011, 98, 083302

${ }^{13}$ H. Uoyama, K. Goushi, K. Shizu, H. Nomura and C. Adachi, Nature, 2012, 492, 234-238.

${ }^{14}$ M. A. Balto, D. F. O’Brien, M. E. Thompson and S. R. Forrest, Phys. Rev. B 1999, 60, $14422-14428$.

${ }^{15}$ (a) M. A. Balto, D. F. O’Brien, Y. You, A. Shoustikov, S. Sibley, M. E. Thomson and S. R. Forrest Nature 1998, 395, 151-154; (b) C. Adachi, M. A. Baldo, M. E. Thompson and S. R. Forrest J. Appl. Phys. 2001, 90, 5048; (c) H. Sasabe and J. Kido, Eur. J. Org. Chem. 2013, 7653-7663.

${ }^{16}$ J.-H. Lee, S.-H. Cheng, S.-J. Yoo, H. Shin, J.-H. Chang, C.-I. Wu, K.-T. Wong and J.-J. Kim, Adv. Funct. Mater., 2015, 25, 361-366.

${ }^{17}$ Y.-K. Wang, S.-H. Li, S.-F. Wu, C.-C. Huang, S. Kumar, Z.-Q. Jiang, M.-K. Fung and L.S. Liao Adv. Funct. Mater., 2018, 28, 1706228.

${ }^{18}$ J.-M. Teng, Y.-F. Wang and C.-F. Chen, J. Mater. Chem. C 2020, 8, 11340-11353.

${ }^{19}$ W. Che, Y. Xie and Zhen Li Asian J. Org. Chem. 2020, 9, 1262-1276.

${ }^{20}$ (a) T.-T. Bui, F. Goubard, M. Ibrahim-Ouali, D. Gigmes and F. Dumur Beilstein J. Org. Chem. 2018, 14, 282-308; (b) S. Scholz, D. Kondakov, B. Lüssem and K. Leo Chem. Rev. $2015, \mathbf{1 1 5}, 8449-8503$.

${ }^{21}$ R. A. Marcus, Rev. Mod. Phys., 1993, 65, 599-610.

${ }^{22}$ P. K. Samanta, D. Kim, V. Coropceanu and J.-L. Brédas, J. Am. Chem. Soc., 2017, 139, 4042-4051.

${ }^{23}$ J.-L. Brédas, D. Beljonne, V. Coropceanu and J. Cornil, Chem. Rev., 2004, 104, 49715004.

${ }^{24}$ Q. Ou, Q. Peng and Z. Shuai, J. Phys. Chem. Lett., 2020, 11, 7790-7797.

${ }^{25}$ Q. Zhu, X. Guo and J. Zhang, J. Comput. Chem., 2019, 40, 1578-1585.

${ }^{26}$ N. Li, F. Ni, Z. Huang, X. Cao and C. Yang, Adv. Opt. Mater., 2021, 2101343.

${ }^{27}$ Y. Xu, P. Xu, D. Hu and Y. Ma, Chem. Soc. Rev., 2021, 50, 1030-1069.

${ }^{28}$ L. Wang, Q. Ou, Q. Peng and Z. Shuai, J. Phys. Chem. A, 2021, 125, 1468-1475.

${ }^{29}$ P.-F. Loos, A. Scemama and D. Jacquemin, J. Phys. Chem. Lett., 2020, 11, 2374-2383.

${ }^{30}$ R. Dhali, D. K. A. Phan Huu, F. Bertocchi, C. Sissa, F. Terenziani and A. Painelli, Phys. Chem. Chem. Phys., 2021, 23, 378-387. 
${ }^{31}$ C. A. Guido, A. Chrayteh, G. Scalmani, B. Mennucci and D. Jacquemin, J. Chem. Theory Comput., 2021, 17, 5155-5164.

${ }^{32}$ S. Achelle and N. Plé, Curr. Org. Synth., 2012, 9, 163-187.

${ }^{33}$ S. Achelle, C. Baudequin and N. Plé, Dyes Pigm., 2013, 98, 575-600.

${ }^{34} \mathrm{~S}$. Achelle, N. Plé and A. Turck, RSC Adv., 2012, 1, 364-388.

${ }^{35}$ S. Achelle, J. Rodríguez-López and F. Robin-le Guen, ChemistrySelect, 2018, 3, $1852-$ 1886.

${ }^{36}$ P. Meti, H.-H. Park and Y.-D. Gong, J. Mater. Chem. C, 2020, 8, 352-379.

${ }^{37}$ G. N. Lipunova, E. V. Nosova, V. N. Charushin and O. N. Chupakhin, Curr. Org. Synth., 2018, 15, 793-814.

${ }^{38}$ S. Achelle, J. Rodríguez-López, F. Bureš and F. Robin-le Guen Chem. Rec., 2020, 20, 440451.

${ }^{39}$ S. Achelle and F. Robin-le Guen, J. Photochem. Photobiol A: Chem., 2017, 348, 281-286.

40 T.-A. Lin, T. Chatterjee, W.-L. Tsai, W.-K. Lee, M.-J. Wu, M. Jiao, K.-C. Pan, C.-L. Yi, C.-L. Chung, K.-T. Wong and C.-C. Wu, Adv. Mater., 2016, 28, 6976-6983.

${ }^{41}$ S. Hirata, Y. Sakai, K. Matsui, H. Tanaka, S. Y. Lee, H. Nomura, N. Nakamura, M. Yasumatsu, H. Nakanotani, Q. Zhang, K. Shizu, H. Miyazaki and C. Adachi, Nat. Mater., 2014, 14, 330-336.

${ }^{42}$ P. Ganesan, R. Ranganathan, Y. Chi, X.-K. Liu, C.-S. Lee, S.-H. Liu, G.-H. Lee, T.-C. Lin, Y.-T. Chen and P.-T. Chou, Chem. Eur. J., 2017, 23, 2858-2866.

${ }^{43}$ Q. Zhang, S. Sun, W. Liu, P. Leng, X. Lv, Y. Wang, H. Chen, S. Ye, S. Zhuang and L. Wang, J. Mater. Chem. C, 2019, 7, 9487-9495.

${ }^{44}$ R. Komatsu, H. Sasabe and J. Kido J. Photonics Energy, 2018, 8, 032108.

${ }^{45}$ L. Yu and C. Yang, J. Mater. Chem. C, 2021, doi: 10.1039/D1TC04397H

46 a) C. Chen, Z. Chi, K. C. Chong, A. S. Batsanov, Z. Yang, Z. Mao, Z. Yan and B. Liu, Nature Mater. 2021, 20, 175-180; b) C. Chen, K. C. Chong, Y. Pan, G. Qi, S. Xu and B. Liu, ACS Mater. Lett. 2021, 3, 1081-1087; c) H.-T. Feng, J. Zeng, P.-A. Yin, X.-D. Wang, Q. Peng, Z. Zhao, J. W. Y. Lam and B. Z. Tang, Nature Commun. 2020, 11, 2617.

47 H. Tanaka, K. Shizu, H. Miyazaki and C. Adachi, Chem. Commun. 2012, 48, 1139211394.

48 Y. Kitamoto, T. Namikawa, D. Ikemizu, Y. Miyata, T. Suzuki, H. Kita, T. Sato and S. Oi, J. Mater. Chem. C 2015, 3, 9122-9130

${ }^{49}$ T. Serevičius, R. Skaisgiris, I. Fiodorova, V. Steckis, J. Dodonova, D. Banevičius, K. Kazlauskas, S. Juršènas and S. Tumkevičius Org. Electron., 2020, 82, 105723.

50 L. Skardziute, J. Dodonova, A. Voitechovičius, J. Jovaisaite, R. Komskis, A. Voitechoviciute, J. Bucevičius, K. Karlauskas, S. Juršènas and S. Tumkevičius Dyes Pigm. 2015, 118, 118-128.

${ }^{51}$ Q. Zhang, S. Xiang, Z. Huang, S. Sun, S. Ye, X. Lv, W. Liu, R. Guo and L. Wang Dyes Pigm., 2018, 115, 51-58.

${ }^{52}$ J. S. Jang, H. L. Lee, K. H. Lee, J. Y. Lee and W. P. Hong, J. Mater. Chem. C, 2021, 9, $2408-2415$

${ }^{53}$ U. Tsiko, O. Bezvikonnyi, G. Sych, R. Keruckiene, D. Volyniuk, J. Simokeitiene, I. Danyliv, A. Bucinskas, X. Tan and J. V. Grazulevicius, J. Adv. Res., 2021, 33, 41-51.

${ }^{54}$ R. Niu, J. Li, D. Liu, R. Dong, W. Wei, H. Tian and C. Shi, Dyes Pigm., 2021, 194, 109581.

${ }^{55}$ S. Tumkevičius, A Voitechovičius and P. Ademenas Chemija, 2012, 23, 61-67.

${ }^{56}$ T. Serevičius, T. Bučūnas, J. Bucevičius, J. Dodonova, S. Tumkevičius, K. Kazlauskas and S. Juršènas J. Mater. Chem. C, 2018, 6, 11128-11136. 
${ }^{57}$ T. Serevičius, J. Dodonova, R. Skaigiris, D. Banevičius, K. Kazlauskas, S. Juršènas and S. Tumkevičius J. Mater. Chem. C, 2020, 8, 11192-11200.

${ }^{58}$ R. Skaisgiris, T. Serevičius, J. Dodonova, D. Banevičius, K. Kazlauskas, S. Tumkevičius and S. Juršènas J. Lumin., 2022, 241, 118473.

59 A. M. Polgar, J. Poisson, N. R. Paisley, C. J. Christopheson, A. C. Reyes and Z. M. Hudson, Macromolecules 2020, 53, 2039-2050.

${ }^{60}$ R. Gómez-Bombarelli, J. Aguilera-Iparraguirre, T. D. Hirzel, D. Duvenaud, D. Maclaurin, M. A. Blood-Forsythe, H. S. Chae, M. Einzinger, D.-G. Ha, t. Wu, G. Markopoulos, S. Jeon, H. Kang, H. Miyazaki, M. Numata, S. Kim, W. Huang, S. I. Hong, M. Baldo, R. P. Adams and A. Aspuru-Guzik Nat. Mater., 2016, 15, 1120-1128.

${ }^{61}$ J. S. Jang, H. L. Lee, K. H. Lee and J. Y. Lee J. Mater. Chem. C, 2019, 7, 12695-12703.

${ }^{62}$ P. Lays dos Santos, D. Chen, P. Rajamalli, T. Matulaitis, D. B. Cordes, A. M. Z. Slawin, D. Jacquemin, E. Zysman-Colman and I. D. W. Samuel ACS Appl. Mater. Interfaces, 2019, 11, 45171-451789.

${ }^{63}$ M. Cai, D. Zhang, J. Xu, X. Hong, C. Zhao, X. Song, Y. Qiu, H. Kaji and L. Duan, ACS Appl. Mater. Interfaces, 2019, 11, 1096-1108.

${ }^{64}$ S.-W. Li, C.-H. Yu, C.-L. Ko, T. Chatterjje, W.-Y. Hung and K.-T. Wong, ACS Appl. Mater. Interfaces, 2018, 10, 12930-12936.

${ }^{65}$ J. Yoon, C. Lee, S H. Park, D. W. Kang, H. Kim, J.-E. Jeong, H. Y. Woo, C. S. Hong, S. Park, M. J. Cho and D. H. Choi, J. Mater. Chem., C 2020, 8, 2196-2204.

${ }^{66}$ Y. Im, M. Kim, Y. J. Cho, J.-A Seo, K. S. Yook and J. Y. Lee, Chem. Mater., 2017, 29, 1946-1963.

${ }^{67}$ K. Nakao, H. Sasabe, R. Komatsu, Y. Hayasaka, T. Ohsawa and J. Kido, Adv. Opt. Mater., $2017, \mathbf{5}, 1600843$.

${ }^{68}$ M Fecková, I. K. Kalis, T. Rosinel, P. le Poul, O. Pytela, M. Klikar, F. Robin-le Guen, F. Bureš, M. Fakis and S. Achelle, Chem. Eur. J., 2021, 27, 1145-1159.

${ }^{69}$ Q. Zhu, X. Guo and J. Zhang, J. Comput Chem., 2019, 40, 1578-1585.

${ }^{70}$ R. Komatsu, H. Sasabe, Y. Seino, K. Nakao and J. Kido, J. Mater. Chem. C, 2016, 4, 22742278.

${ }^{71}$ R. Komatsu, T. Ohsawa, H. Sasabe, K. Nakao, Y. Hayasaka and J. Kido, ACS Appl. Mater. Interfaces, 2017, 9, 4742-4749.

${ }^{72}$ C. H. Lee, S. H. Choi, S. J. Oh, J. H. Lee, J. W. Shim, C. Adachi and S. Y. Lee RSC Adv., 2020, 10, 42897-42902.

${ }^{73}$ T. Serevičius, R. Skaisgiris, I. Fiodorova, G. Kreiza, D. Banevičius, K. Kazlauskas, S. Tumkevičius and S. Juršènas, J. Mater. Chem. C, 2021, 9, 836-841.

${ }^{74}$ H. Wang, C. Zhang, G. Shan, Z. Yu, S. Liu, L. Zhang, W. Xie and H. Zhao, Adv. Optical Mater., 2019, 7, 1801718.

${ }^{75}$ I. S. Park, H. Komiyama and T. Yasuda Chem. Sci., 2017, 8, 953-960.

${ }^{76}$ M. Hempe, N. A. Kukhta, A. Damos, M. A. Fox, A. S. Batsanov, A. P. Monkman and M. R. Bryce, Chem. Mater. 2021, 33, 3066-3080.

${ }^{77}$ I. S. Park, J. Lee and T. Yasuda, J. Mater. Chem. C, 2016, 4, 7911-7916.

${ }^{78}$ B. Li, Z. Li, T. Hu, Y. Zhang, Y. Wang, Y. Yi, F. Guo and L. Zhao, J. Mater. Chem. C, 2018, 6, 2351-2359.

${ }^{79}$ M. Liu, R. Komatsu, X. Cai, K. Hotta, S. Sato, K. Liu, D. Chen, Y. Kato, H. Sasabe, S. Ohisa, Y. Suzuri, D. Yokayama, S.-J. Su and J. Kido, Chem. Mater., 2017, 29, 8630-8636.

${ }^{80}$ Q. Zhang, S. Sun, W. J. Chung, S. J. Yoon, Y. Wang, R. Guo, S. Ye, J. Y. Lee and L. Wang, J. Mater. Chem. C, 2019, 7, 12248-12255.

${ }^{81}$ Y. Wada, H. Nakagawa and H. Kaji, Chem Asian J. 2021, 16, 1073-1076.

${ }^{82}$ T. J. Penfold, F. B. Dias and A. P. Monkman, Chem. Commun., 2018, 54, 3926-3935. 
${ }^{83}$ O. Bezvikonnyi, D. Gudeika, D. Volyniuk, V. Mimaite, B. R. Sebastien and J. V. Grazulevicius, J. Lumin. 2019, 206, 250-259.

${ }^{84}$ Y.-F. Shen, M. Li, W.-L. Zhao, Y.-F. Wang, H.-Y. Lu and C.-F. Chen, Mater. Chem. Front. 2021, 5, 834-842.

${ }^{85}$ T. Serevičius, R. Skaigiris, J. Dodonova, L. Jagintavičius, D. Banevičius, K. Kazlauskas, S. Tumkevičius and S. Juršènas, ACS Appl. Mater. Interfaces 2020, 12, 10727-10736.

${ }^{86}$ T. Serevičius, R. Skaigiris, J. Dodonova, L. Jagintavičius, J. Bucevičius, K. Kazlauskas, S. Juršènas and S. Tumkevičius, Chem. Commun. 2019, 55, 1975-1978.

${ }^{87}$ S. Kang, S. H. Jeon, Y. M. Cho, Y. J. Kim, T. Kim and J. Y. Lee, Org. Electron., 2020, 78, 105595.

${ }^{88}$ K. Wu, T. Zhang, L. Zhan, C. Zhong, S. Gong, N. Jiang, Z.-H. Lu and C. Yang, Chem. Eur. J. 2016, 22, 10860-10866.

${ }^{89}$ Y. Xiang, P. Li, S. Gong, Y-H. Huang, C-Y. Wang, C. Zhong, W. Zheng, Z. Chen, W-K. Lee, X. Yin, C.-C. Wu and C. Yang, Sci.Adv. 2020, 6, eaba7855.

${ }^{90}$ T. Serevičius, R. Skaisgiris, J. Dodonova, K. Kazlauskas, S. Juršènas and S. Tunkevičius, Phys. Chem. Chem. Phys., 2020, 22, 265-272.

${ }^{91}$ P. Pander, R. Daniels, A. V. Zaytsev, A. Horn, A. Sil, T. J. Penfold, J. A. G. Williams, V. N. Kozhevnikov and F. B. Dias, Chem. Sci., 2021, 12, 6172-6180.

${ }^{92}$ P. Pander, A. V. Zaytsev, A. Sil, J. A. G. Williams, P.-H. Lanoe, V. N. Kozhevnikov and F. B. Dias, J. Mater. Chem. C, 2021, 9, 10276-10287.

${ }^{93}$ P. Pander, A. V. Zaytsev, A. Sil, J. A. G. Williams, V. N. Kozhevnikov and F. B. Dias, J. Mater. Chem. C, 2021, doi: 10.1039/D1TC05026E

${ }^{94}$ M. Z. Shafikov, R. Martinscroft, C. Hodgson, A. Hayer, A. Auch and V. N. Kozhevnikov, Inorg. Chem., 2021, 60, 1780-1789.

${ }^{95}$ P. Rajamalli, D. Chen, S. M. Suresh, Y. Tsuchiya, C. Adachi and E. Zysman-Colman, Eur. J. Org. Chem., 2021, 2285-2293.

${ }^{96}$ L. Salah, M. K. Etherington, A. Shuaib, A. Danos, A. A. Nazeer, B. Ghazal, A. Prlj, A. T. Turley, A. Mallick, P. R. McGonigal, B. F. E. Curchod, A. P. Monkman and S. Makhseed, J. Mater. Chem. C, 2021, 9, 189-198.

${ }^{97}$ J. Liu, K. Zhou, D. Wang, C. Deng, K. Duan, Q. Ai and Q. Zhang, Front. Chem., 2019, 7, 312.

${ }^{98}$ H. Li, T. Yang, J. Wang, N. Xie, Q. Wang, Y. Xu, Y. Zhao and B. Liang, ChemPlusChem, 2021, 86, 95-102.

${ }^{99}$ Y. Kato, H. Sasabe, Y. Hayasaka, Y. Watanabe, H. Arai and J. Kido, J. Mater. Chem. C, 2019, 7, 3146-3149.

${ }^{100}$ S. Krotkus, T. Matulaitis, S. Diessing, G. Copley, E. Archer, C. Keum, D. B. Cordes, A. M. Z. Slawin, M. C. Gather, E. Zysman-Colman and I. D. W. Samuel, Front. Chem., 2021, 8, 572962.

${ }^{101}$ A. Arjona-Esteban, B. Szafranowska and J. Ochmann in TADF Technology for efficient OLEDs: status and challenges from industrial point of view, IntechOpen Book series, doi: 10.5772/intechopen. 86534

${ }_{102}$ M. A. Bryden and E. Zysman-Colman Chem. Soc. Rev. 2021, 50, 7587-7680.

${ }^{103}$ V.-N. Nguyen, A. Kumar, M. H. Lee and J. Yoon Coord. Chem. Rev. 2020, 425, 213545.

${ }^{104}$ W. Ma, Y. Su, Q. Zhang, C. Deng, L. Pasquali, W. Zhu, Y. Tian, P. Ran, Z. Chen, G. Yang, G. Liang, T. Liu, H. Zhu, P. Huang, H. Zhong, K. Wang, S. Peng, J. Xia, H. Liu, X. Liu and Y. Yang, Nature Mater. 2021, in press, doi: 10.1038/s41563-021-01132-X 